\title{
RADIOCARBON BEYOND THIS WORLD
}

\author{
A J Timothy Jull ${ }^{1} \bullet$ Devendra Lal $^{2} \bullet$ George S Burr $^{1} \bullet$ Philip A Bland $^{3} \bullet$ Alexander W R Bevan ${ }^{4}$ \\ J Warren Beck ${ }^{1}$
}

ABSTRACT. In this paper, we review the production of radiocarbon and other radionuclides in extraterrestrial materials. This radioactivity can be produced by the effects of solar and galactic cosmic rays on solid material in space. In addition, direct implantation at the lunar surface of ${ }^{14} \mathrm{C}$ and other radionuclides can occur. The level of ${ }^{14} \mathrm{C}$ and other radionuclides in a meteorite can be used to determine its residence time on the Earth's surface, or "terrestrial age". ${ }^{14} \mathrm{C}$ provides the best tool for estimating terrestrial ages of meteorites collected in desert environments. Age control allows us to understand the time constraints on processes by which meteorites are weathered, as well as mean storage times. Third, we discuss the use of the difference in ${ }^{14} \mathrm{C} /{ }^{12} \mathrm{C}$ ratio of organic material and carbonates produced on other planetary objects and terrestrial material. These differences can be used to assess the importance of distinguishing primary material formed on the parent body from secondary alteration of meteoritic material after it lands on the earth.

\section{INTRODUCTION}

Cosmic rays interact with all solid objects in the solar system to produce radioactivity, from dust grains and meteorites to planetary bodies. Besides the well-known production of radiocarbon in the terrestrial atmosphere, spallation reactions of galactic (GCR) and solar (SCR) cosmic-ray particles on oxygen and silicon, and some other target elements result in the production of many radionuclides. This radioactivity produced in space can give us important information on the variations of GCR, SCR and also energetic particles emitted by the Sun. These high-energy reactions are different from the atmospheric production of ${ }^{14} \mathrm{C}$ by thermal neutron effects on nitrogen. In this paper, we review several aspects of extraterrestrial or "cosmogenic" ${ }^{14} \mathrm{C}$.

The production of this radionuclide in space can be used for several important applications, which we will discuss in this paper, specifically:

1. Lunar samples. We can use the levels of cosmic-ray-produced ${ }^{14} \mathrm{C}$ in lunar samples, to estimate the effects of SCR and GCR production and the possibility of fluctuations of SCR in the past.

2. Terrestrial ages of meteorites. We can use the ${ }^{14} \mathrm{C}$ produced in space as a method to measure the terrestrial residence time (terrestrial age) of meteorites after they fall to earth. The level produced in space is used as the "zero age" and one can then calculate the terrestrial age from the amount of ${ }^{14} \mathrm{C}$ remaining.

3. Contamination studies of meteorites. A third application of considerable interest is useful in the determination the relative amounts of terrestrial contamination in organic compounds found in some meteorites. Because of the great interest in Martian meteorites that was generated by the work of McKay et al. (1996), a way of distinguishing between indigenous organic material and contamination is necessary. In this case, we can use the difference between ${ }^{14} \mathrm{C}$ produced in space and the levels produced in the terrestrial atmosphere to identify different sources of carbon in these samples. Recent carbon produced at the surface of the earth from atmospheric sources will have a much different signature than spallogenic carbon produced in organic or car-

\footnotetext{
${ }^{1}$ NSF-Arizona AMS Laboratory, University of Arizona, 1118 East Fourth St., Tucson, Arizona 85721, USA.

E-mail: jull@u.arizona.edu.

${ }^{2}$ Scripps Institution of Oceanography, Geological Research Division, University of California San Diego, La Jolla, California 92093, USA

${ }^{3}$ Natural History Museum, Cromwell Road, London SW7 5DB, England

${ }^{4}$ Western Australian Museum, Francis St., Perth, WA 6000, Australia
} 
bonate materials in space. Hence, these differences can be used as a marker of origin of this carbon and allow us to distinguish these components.

In this paper we will review these three important applications of ${ }^{14} \mathrm{C}$ in extraterrestrial materials and give some examples of their applications.

\section{RADIOCARBON IN LUNAR SAMPLES}

Our first example is ${ }^{14} \mathrm{C}$ produced on the surface of the Moon. Lunar materials, both soils and rock surfaces provide long records of continuous production of radionuclides by GCR and SCR spallation. If we can obtain the records of different radionuclides that integrate different periods of time, we can estimate cosmic-ray intensities and variations of SCR fluxes in the past (see Reedy 1980; Reedy and Marti 1991) and possibly also differences in spectral shape. Fink et al. (1998) and Jull et al. (1998a) have summarized results of many radionuclides that have been used to determine variations of SCR fluxes in the past.

Several mean lives of the radionuclide, i.e. for ${ }^{14} \mathrm{C}$ about $20-30 \mathrm{ka}$ of continuous exposure is required to reach a saturation level, as this cosmic-ray-produced ${ }^{14} \mathrm{C}$ will build up according to an exponential increase as shown in Equation 1

$$
N_{14}=\frac{P}{\lambda}\left(1-e^{-\lambda t}\right)
$$

Here, the production rate, $P$, is a combination of production from both SCR and GCR. $N_{14}$ is the number of ${ }^{14} \mathrm{C}$ atoms, $\lambda$ is the ${ }^{14} \mathrm{C}$ decay constant, and $t$ is time. The production rate is dependent on the depth of the sample in the rock or core and geometry. The build-up time for ${ }^{14} \mathrm{C}$ is much less than the exposure times at the lunar surface (which are in the millions of years, estimated from long-lived radionuclides) and also erosion or gardening by micrometeorite impacts. These processes occur on a time-scale of a few millimeters per million years (Langevin et al. 1982) and do not disturb ${ }^{14} \mathrm{C}$, but they are important in the understanding of longer-lived nuclide distributions. In the past, some ${ }^{14} \mathrm{C}$ work was done with gas counters, on samples from the top few centimeters of lunar rocks 12002 (Boeckl 1972) and 12053 (Begemann et al. 1972) and these suggested high levels at the very surface. These early counter-measurements data had relatively large uncertainties due to the size of the samples studied. Boeckl (1972) used the high surface ${ }^{14} \mathrm{C}$ values as evidence for an enhanced solarproton $4 \pi$ flux of 200 protons $/ \mathrm{cm}^{2} / \mathrm{s}\left(\mathrm{E}_{\mathrm{p}}>10 \mathrm{MeV} ; \mathrm{R}_{0}=100 \mathrm{MV}\right)$ over the last $\sim 10 \mathrm{ka}$. Further, Begemann et al. (1972) had suggested that the very surface layer of lunar samples could be implanted with solar-wind ${ }^{14} \mathrm{C}$, and this could account for the enhanced surface activity in rock 12002 . Fireman (1977) also studied surface enrichments which he ascribed to solar-wind implantation of ${ }^{14} \mathrm{C}$.

Measurements on finer slices of rock had to wait for the development of accelerator mass spectrometry (AMS) and only in the last decade have the small size requirements of AMS measurements allowed studies of the production rate and depth dependence of ${ }^{14} \mathrm{C}$ in millimeter-sized slices of lunar rocks (see Jull et al. 1992, 1998a). Previous work with ${ }^{14} \mathrm{C}$ in lunar samples has identified three extraterrestrial sources of the ${ }^{14} \mathrm{C}$ observed in lunar samples-production by nuclear reactions induced by GCR or SCR particles or implantation from either the solar wind (SW) or solar energetic particles (SEP).

1. Production of ${ }^{14} \mathrm{C}$ by GCR in extraterrestrial materials. Armstrong and Alsmiller (1971) and Reedy and Arnold (1972) developed models for calculation of the production of ${ }^{14} \mathrm{C}$ by cosmicray effects in the lunar surface. For a long time, models for the GCR production of ${ }^{14} \mathrm{C}$, based on 
the work of Reedy and Arnold (1972) did not result in a good fit to lunar samples. Hence, Born (1973) and Rao et al. (1994) had to increase calculated production rates to fit their experimental data. Over the years, cross sections have been revised and improved using AMS studies of artificially-irradiated foils (e.g. Jull et al. 1989a, 1998a; Sisterson et al. 1997a, 1997b, 1997c). A new model by Masarik and Reedy (1994) was used to calculate production rates of ${ }^{14} \mathrm{C}$ by GCR particles in the meteorite Knyahinya ${ }^{1}$ (L5 chondrite) as a function of depth (Jull et al. 1994). This model now gives good agreement $(\sim 10 \%)$ with measured values for both meteorites and lunar samples (see inter alia, Jull et al. 1998b; Wieler et al. 1996). Figure 1 shows some sample production rates for a typical meteoroid of different sizes irradiated in space.

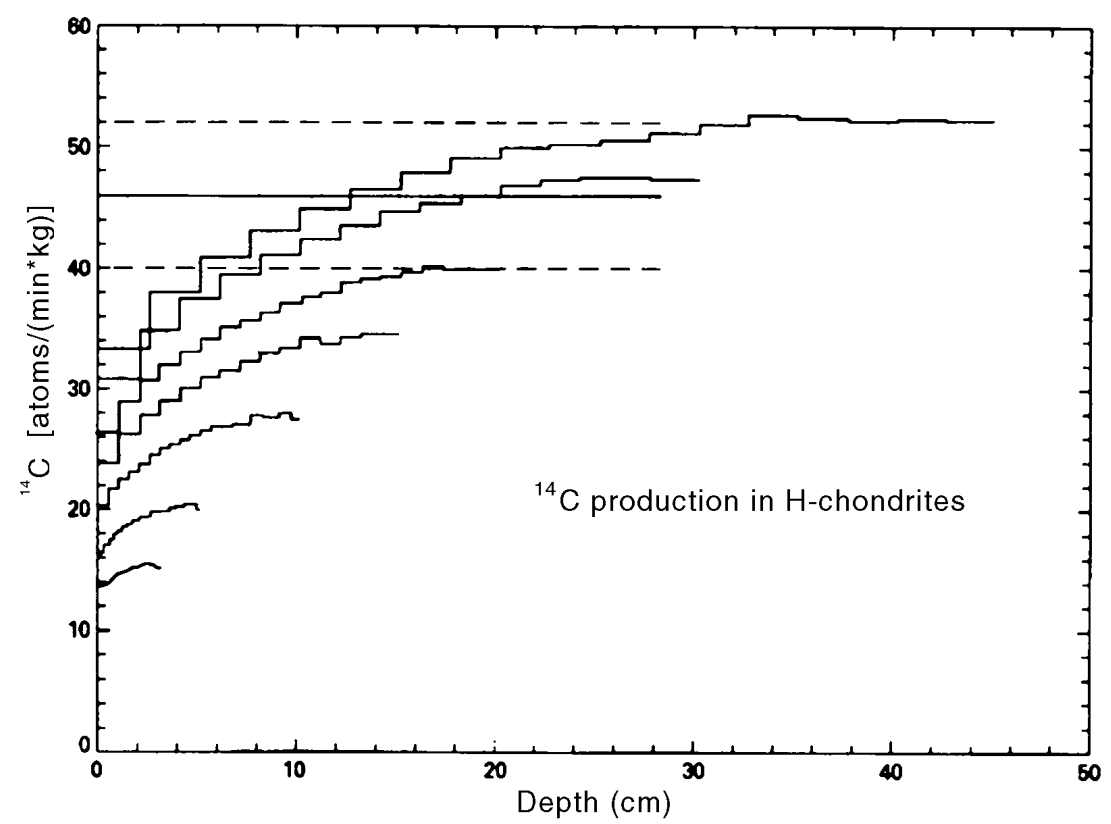

Figure 1 Depth dependence of GCR production of ${ }^{14} \mathrm{C}$ in meteoroids of different radii (from Wieler et al. 1996). The horizontal line is the mean value observed for $\mathrm{H} 6$ falls, with the dashed lines showing the range observed.

2. SCR Effects. Solar-cosmic-ray particles, $>98 \%$ protons, with energies of tens to hundreds of $\mathrm{MeV}$, have a range of $\sim 1 \mathrm{~cm}$ in rocks. The SCR flux can be approximated (Reedy and Arnold 1972) as a distribution in rigidity units of the form

$$
\mathrm{d} J / \mathrm{dR}=\operatorname{kexp}\left(-\mathrm{R} / \mathrm{R}_{0}\right)
$$

where $\mathrm{J}$ is the flux, $\mathrm{R}$ is the rigidity ( $\mathrm{pc} / \mathrm{Ze}$ ) of the particles, $\mathrm{R}_{0}$ is a spectral shape parameter, given in units of megavolts (MV), and $\mathrm{k}$ is a constant. Fluxes for SCR are quoted for proton energies $>10 \mathrm{MeV}$ and for a $4 \pi$ solid angle, defined as $\mathrm{J}_{10}$, and has units of protons $/ \mathrm{cm}^{2} / \mathrm{s}$. Values of $\mathrm{R}_{0}$ in the range 70 to $125 \mathrm{MV}$ have been fitted to a variety of radionuclide data from

\footnotetext{
${ }^{1}$ Meteorites are named by the Nomenclature Committee of the Meteoritical Society and reported in the "Meteoritical Bulletin", published in Meteoritics and Planetary Science (e.g. Grossman 1999). Traditionally, meteorites are named for the nearest post office or named geologic feature. Due to the proliferation of meteorites from desert regions and Antarctica, other more generic names and numbers are often assigned to these meteorites.
} 
lunar samples (see for example Reedy and Marti 1991; Rao et al. 1994; Fink et al. 1998; Jull et al. 1998a). SCR effects in meteorites are usually not observed since the outer surface of the meteoroid is ablated during atmospheric entry. The best example of SCR production is ${ }^{26} \mathrm{Al}$ in the Salem meteorite (Nishiizumi et al. 1990). There has been no measurement of excess ${ }^{14} \mathrm{C}$ attributed to SCR in meteorites. One interesting question is whether this spectral shape is actually a good model for SCR at all energies (Lingenfelter and Hudson 1980).

3. Implanted energetic particles: The solar wind is a stream of particles, mostly protons, emitted by the Sun with an average flux at $1 \mathrm{AU}$ of $\sim 2 \times 10^{8} \mathrm{protons} / \mathrm{cm}^{2} / \mathrm{s}$ (Keays et al. 1970) and $\sim 1$ $\mathrm{keV} / \mathrm{amu}$ in energy. The range of such particles in rock is $\sim 30-40 \mathrm{~nm}$ in rock (Ziegler et al. 1989). There is also a possibility of implanted of higher-energy (up to 10's of MeV) particles emitted during solar flares (e.g. Wieler et al. 1996; Nishiizumi et al. 1997). As already mentioned, Begemann et al. (1972) first suggested that the very surface layer of lunar samples could be implanted with solar ${ }^{14} \mathrm{C}$. Fireman et al. $(1976,1977)$ found higher than expected levels of ${ }^{14} \mathrm{C}$ in the $600-1000{ }^{\circ} \mathrm{C}$ temperature fractions of the Apollo 11 soil 10084 and Apollo 17 trench soils 73221,73241 and 73261 , which they interpreted as implanted solar wind ${ }^{14} \mathrm{C}$. If implanted from the solar wind and not another source, this result would imply a ${ }^{14} \mathrm{C} /{ }^{1} \mathrm{H}$ ratio in the solar wind of $\sim 5 \times 10^{-11}$. Jull et al. (1995a) reported on an experiment that confirmed the existence of this implanted ${ }^{14} \mathrm{C}$ component and concluded that there was an implanted ${ }^{14} \mathrm{C}$ flux on the very surfaces of lunar rocks and soil of 4 to $7 \times 10^{-6}{ }^{14} \mathrm{C} / \mathrm{cm}^{2} / \mathrm{s}$, which is equivalent to a $2-3.5$ $\times 10^{-14}{ }^{14} \mathrm{C} / \mathrm{H}$ ratio. However, in this work the possibility of sources other than just the solar wind were considered. These results suggested that this was good evidence for an implanted ${ }^{14} \mathrm{C}$ component in the surface soil and rock.

\section{Laboratory Procedures for ${ }^{14} \mathrm{C}$ Extraction from Lunar Samples and Meteorites}

Cosmogenic ${ }^{14} \mathrm{C}$ can be extracted from meteorites, lunar rocks, or soils by fusion of the rock powder with iron (which is used to enhance combustion) in an oxidizing environment. Lunar samples are crushed, if not already a powder, and several grams of iron chips are added to enhance combustion. The meteorite samples were crushed to a powder, weighed, and treated with $100 \%$ phosphoric acid to remove carbonates from the material. In addition, the samples are preheated to $500{ }^{\circ} \mathrm{C}$ in air to remove contaminants due to organics and adsorbed $\mathrm{CO}_{2}$. The gas from the acid etching was collected and the ${ }^{14} \mathrm{C}$ ages of this material was measured. The residue was washed with distilled water and dried. This material was then placed in an alumina crucible and mixed with about $5 \mathrm{~g}$ of iron chips used as a combustion accelerator. The crucible is placed in an oven at $500{ }^{\circ} \mathrm{C}$ for $1 \mathrm{hr}$. The crucible is then placed in an RF furnace and heated to melting in a flow of oxygen. Any evolved gases are passed over $\mathrm{MnO}_{2}$ to remove sulfur compounds and $\mathrm{CuO} / \mathrm{Pt}$ at $450{ }^{\circ} \mathrm{C}$ to oxidize all carbonaceous gases such as $\mathrm{CO}$ and $\mathrm{CH}_{4}$ to $\mathrm{CO}_{2}$. The volume of the gas is measured, and the gas is diluted with about $0.5-2.5 \mathrm{~cm}^{3}$ of ${ }^{14} \mathrm{C}$-free $\mathrm{CO}_{2}$, as a carrier. This gas is finally converted to graphite powder over an Fe catalyst, which is then pressed into an AMS target holder. The target is mounted in a 32position wheel in the AMS ion source and the sample ${ }^{14} \mathrm{C} /{ }^{13} \mathrm{C}$ is compared to that in known NIST standards. Procedures for the AMS analyses have been reported by Jull et al. (1990, 1993a) and details of the calculations by Donahue et al. (1990). Samples of graphite as small as $100 \mu \mathrm{g}$ are then analyzed by AMS. The basic studies on Bruderheim, other meteorites, and blank rock samples were published in Jull et al. (1989b, 1993a, 1994, 1998b).

\section{${ }^{14} \mathrm{C}$ in a Lunar Rock Surface}

In Jull et al. (1998a), we reported on ${ }^{14} \mathrm{C}$ in a series of samples from lunar rock 68815 , collected from the Apollo 16 site. With a rock, we should expect to obtain a complete SCR profile indepen- 
dent of any gardening or loss of material which we might expect in a soil core top. Erosion by micrometeorites, of the order of $\mathrm{mm} / \mathrm{million}$ years, ought not to affect ${ }^{14} \mathrm{C}$. Rock 68815 was removed from the top of a large boulder at the Apollo 16 site (see Figure 2 in Color Plate 3.). Results of our measurements are shown in Figure 3, from a surface value of about $66 \mathrm{dpm} / \mathrm{kg}$. The surface profile which shows a decline of ${ }^{14} \mathrm{C}$ to about a depth of $3 \mathrm{~g} / \mathrm{cm}^{2}$, due to SCR production of ${ }^{14} \mathrm{C}$ as well as GCR. The subsequent increase to about $50 \mathrm{~g} / \mathrm{cm}^{2}$ depth is due to GCR production alone. The results show that our measurements give a similar trend of ${ }^{14} \mathrm{C}$ with depth in the rock as observed previously in Apollo 12 lunar rocks, numbered 12053 and 12002, by Begemann et al. (1972) and Boeckl (1972), but with more detail. We also studied two very-surface patina samples that covered a larger area of rock, which gave a similar result. The results do not show the very high surface value observed by Jull et al. (1995a); we shall return to this observation later.

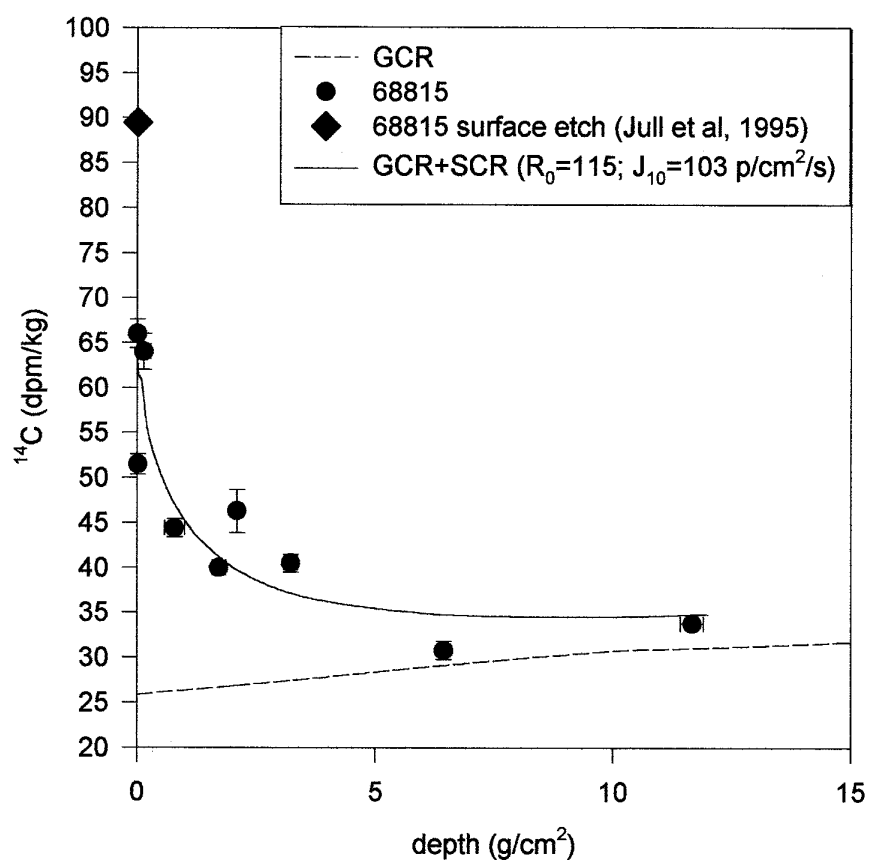

Figure 3 Depth dependence of ${ }^{14} \mathrm{C}$ due to SCR and GCR production in the surface of lunar rock 68815

The measurements for ${ }^{14} \mathrm{C}$ production in 68815 as a function of depth are illustrated in Figure 3 . Jull et al. (1998a) reported the best fits to the data for $\mathrm{R}_{0}$ of $115 \mathrm{MV}$ and $\mathrm{J}_{10}$ of 103 protons $/ \mathrm{cm}^{2} / \mathrm{s}$. However, they also found other reasonable fits for different values of $\mathrm{R}_{0}$ from 100 to $130 \mathrm{MV}$, with equivalent values of $J_{10}$ of 130 to $88 \mathrm{p} / \mathrm{cm}^{2} / \mathrm{s}$, since there are a series of solutions for both $\mathrm{J}_{10}$ and $\mathrm{R}_{0}$ which fit this spectrum. However, all fits gave a flux of $19 \mathrm{p} / \mathrm{cm}^{2} / \mathrm{s}$ for $\mathrm{J}(\mathrm{E}>57 \mathrm{MeV})$. The best fits were found for spectra with the model energy distribution used by Reedy and Arnold (1972). The best fit $\mathrm{R}_{0}$ was that with the smallest standard deviation of the observed/calculated ratios of SCR activities using calculated SCR production rates for a wide range of Ro values. The average ratio for the best-fit Ro was then used to adjust the arbitrary solar-proton flux used in the calculation to get the best-fit flux. For the Apollo 15 soil cores, Jull et al. (1998a) reported the best fit used the data between 0.8 and $5 \mathrm{~g} / \mathrm{cm}^{2}$ with the ${ }^{14} \mathrm{C}$ activity of the surface sample being significantly lower than 
calculated. Hence, we can fit most data from rock 68815 and the soil cores to the calculated SCR profiles. If there is an implanted component, as discussed by Jull et al. (1995a), this could affect the observations on the very surface.

Table 1 Radionuclides used in extraterrestrial studies

\begin{tabular}{lll}
\hline Nuclide & Half-life & References \\
\hline${ }^{14} \mathrm{C}$ & $5.73 \mathrm{ka}$ & Begemann et al. (1972); Boeckl (1972); Jull et al. (1989b, 1995a, 1995b) \\
${ }^{59} \mathrm{Ni}$ & $76 \mathrm{ka}$ & Lanzerotti et al. (1973) \\
${ }^{41} \mathrm{Ca}$ & $\sim 100 \mathrm{ka}$ & Fink et al. (1998) \\
${ }^{81} \mathrm{Kr}$ & $229 \mathrm{ka}$ & Reedy and Marti (1991) \\
${ }^{36} \mathrm{Cl}$ & $300 \mathrm{ka}$ & Nishiizumi et al. (1989, 1995) \\
${ }^{26} \mathrm{Al}$ & $700 \mathrm{ka}$ & Kohl et al. (1978); Nishiizumi et al. (1990, 1995); Fink et al. (1998) \\
${ }^{10} \mathrm{Be}$ & $1.5 \mathrm{Ma}$ & Nishiizumi et al. (1988, 1990, 1995, 1997); Fink et al. (1998) \\
${ }^{53} \mathrm{Mn}$ & $3.7 \mathrm{Ma}$ & Kohl et al. (1978); Nishiizumi et al. (1990) \\
${ }^{21} \mathrm{Ne},{ }^{22} \mathrm{Ne},{ }^{38} \mathrm{Ar}$ & Stable & Rao et al. (1994) \\
\hline
\end{tabular}

Table 2 Solar-proton spectral parameters and $4 \pi$ integral fluxes $\left(\mathrm{p} / \mathrm{cm}^{2} / \mathrm{s}\right)$ above various energies (in $\mathrm{MeV}$ ) determined from radionuclides in lunar samples (adapted from Jull et al. 1998a)

\begin{tabular}{|c|c|c|c|c|c|c|}
\hline Time range & Nuclide & References & $\mathrm{R}_{0}(\mathrm{MV})$ & $\mathrm{E}>10$ & $\mathrm{E}>30$ & $E>60$ \\
\hline 1954-1964 & ${ }^{22} \mathrm{Na},{ }^{55} \mathrm{Fe}$ & Reedy (1977) & 100 & 378 & 136 & 59 \\
\hline $2 \times 10^{4} \mathrm{yr}$ & ${ }^{14} \mathrm{C}$ & Jull et al. (1998a) & $110-115$ & $103 \pm 5$ & 42 & 17 \\
\hline \multirow[t]{2}{*}{$1 \times 10^{5} \mathrm{yr}$} & ${ }^{41} \mathrm{Ca}^{\mathrm{a}}$ & Klein et al. (1990) & 70 & 120 & 28 & 7 \\
\hline & & Fink et al. (1998) & 80 & 200 & 56 & 16 \\
\hline $3 \times 10^{5} \mathrm{yr}$ & ${ }^{81} \mathrm{Kr}^{\mathrm{a}}$ & Reedy and Marti (1991) & $\sim 85$ & - & - & 14 \\
\hline $5 \times 10^{5} \mathrm{yr}$ & ${ }^{36} \mathrm{Cl}^{\mathrm{a}}$ & Nishiizumi et al. (1995) & $\sim 75$ & 100 & 26 & 7 \\
\hline $1 \times 10^{6} \mathrm{yr}$ & ${ }^{26} \mathrm{Al}^{2}$ & Kohl et al. (1978) & 100 & 70 & 25 & 9 \\
\hline \multirow[t]{3}{*}{$1 \times 10^{6} \mathrm{yr}$} & ${ }^{10} \mathrm{Be},{ }^{26} \mathrm{Al}^{\mathrm{b}}$ & Nishiizumi et al. (1995) & 75 & 100 & 26 & 7 \\
\hline & ${ }^{10} \mathrm{Be},{ }^{26} \mathrm{Al}$ & Michel et al. (1996) & 125 & 55 & 24 & 11 \\
\hline & & Fink et al. (1998) & 100 & 89 & 32 & 12 \\
\hline $2 \times 10^{6} \mathrm{yr}$ & ${ }^{10} \mathrm{Be},{ }^{26} \mathrm{Al}^{\mathrm{b}}$ & Nishiizumi et al. (1988) & $>70$ & — & $\sim 35$ & $\sim 8$ \\
\hline $6 \times 10^{7} \mathrm{yr}$ & ${ }^{53} \mathrm{Mn}$ & Kohl et al. (1978) & 100 & 70 & 25 & 9 \\
\hline$\sim 2 \times 10^{6} \mathrm{yr}^{\mathrm{c}}$ & ${ }^{21,22} \mathrm{Ne},{ }^{38} \mathrm{Ar}$ & Rao et al. (1994) & $80-90$ & $58-87$ & $\sim 22$ & $\sim 7$ \\
\hline
\end{tabular}

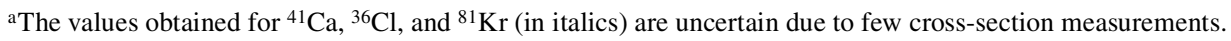

${ }^{b}$ The determinations for ${ }^{26} \mathrm{Al}$ before 1996 are based on old cross sections and could change using recently measured cross sections (Michel et al. 1996; Sisterson et al. 1997c).

${ }^{\mathrm{c}}$ The determinations based on stable nuclides depends on the erosion rate model used by Rao et al. (1994), who assumed an erosion rate of 1-2 mm/Ma and the estimate exposure age of $\sim 2 \mathrm{Ma}$ based on ${ }^{10} \mathrm{Be}$ in 68815 (Nishiizumi et al. 1988).

\section{Variations in the SCR Flux}

In Table 2, we list for comparison some $\mathrm{R}_{0}$ and flux estimates which were obtained from measurements of several long-lived and stable isotopes in lunar rocks (see Jull et al. 1998a). The values of $\mathrm{R}_{0}$ and flux obtained in the work from ${ }^{14} \mathrm{C}$ measurements are usually larger than the equivalent values from studies using longer-lived nuclides, except ${ }^{41} \mathrm{Ca}$. In addition, for some nuclides, cross sections are not sufficiently well-known to allow us to determine uniquely both $\mathrm{R}_{0}$ and $\mathrm{J}_{10}$. However, the fact that the rigidity parameter $\mathrm{R}_{0}$ and fluxes for the relatively short-lived ${ }^{14} \mathrm{C}$ (Jull et al. 1998a) and ${ }^{41} \mathrm{Ca}$ (Fink et al. 1998) are higher than other nuclides, indicates to us that the SCR flux over the last $\sim 10,000$ to $100,000 \mathrm{yr}$ must have been greater than for longer time-periods. This is particularly 
clear for the $\mathrm{E}>60 \mathrm{MeV}$ particles. To summarize the best fits of $\mathrm{SCR}{ }^{14} \mathrm{C}$, this was found for a higher $\mathrm{R}_{0}$ of 110 to $115 \mathrm{MV}$ and a $\mathrm{J}_{10}$ flux of $108-98$ protons $/ \mathrm{cm}^{2} / \mathrm{s}$, respectively.

Million-year time scales from ${ }^{53} \mathrm{Mn},{ }^{10} \mathrm{Be}$ and ${ }^{26} \mathrm{Al}$ studies. The first estimates of the SCR flux had determined a value of $\mathrm{J}_{10}$ of $\sim 70$ protons $/ \mathrm{cm}^{2} / \mathrm{s}$ from ${ }^{53} \mathrm{Mn}$ and ${ }^{26} \mathrm{Al}$ measurements in rock 68815 , with a spectral shape parameter $\mathrm{R}_{0}$ of $100 \mathrm{MV}$ (Kohl et al. 1978). However, these authors also noted that this combination of flux $(>10 \mathrm{MeV}), \mathrm{R}_{0}$, and erosion rates was not a unique solution. Later, Nishiizumi et al. (1988) measured ${ }^{10} \mathrm{Be}$ in lunar rock 68815 , and deduced a higher flux at lower $\mathrm{R}_{0}$, using this radionuclide. This cast some doubt on existing cross section measurements. Using recent measurements of cross sections for the production of ${ }^{10} \mathrm{Be}$ by protons (Sisterson et al. 1997a,b,c; Bodemann et al. 1993; Schiekel et al. 1996), a production rate for ${ }^{10} \mathrm{Be}$ in the surface layer of 68815 to be $\sim 25 \%$ higher than those calculated using earlier estimates can be determined. This resulted in a value for $\mathrm{R}_{0}=70 \mathrm{MV}$ and $\mathrm{J}_{10}$ of $\sim 100$ protons $/ \mathrm{cm}^{2} / \mathrm{s}$ (see Jull et al. 1998a). The latest cross sections for ${ }^{10} \mathrm{Be}$ and ${ }^{26} \mathrm{Al}$ were used by Fink et al. (1998) in another lunar rock, 74275. Also recently, Michel et al. (1996) estimated $\mathrm{J}_{10}$ of 55 protons $/ \mathrm{cm}^{2} / \mathrm{s}$ for $\mathrm{R}_{0}=125 \mathrm{MV}$ from ${ }^{10} \mathrm{Be}$ and ${ }^{26} \mathrm{Al}$ cross sections and reported profiles. The studies by Fink et al. (1998) and Nishiizumi et al. (1995) give $\mathrm{J}_{10}$ values within $\sim 15 \%$ of our estimates of flux from ${ }^{14} \mathrm{C}$, but not for the same $\mathrm{R}_{0}$. Several radionuclides, including ${ }^{14} \mathrm{C}$, are produced by reactions with threshold energies of 30 to $60 \mathrm{MeV}$. Thus, radioisotopes having a halflives longer than $10^{6} \mathrm{yr}$ generally appear to have lower $\mathrm{J}_{10}$ and lower $\mathrm{R}_{0}$ than our new estimates based on the shorter-lived ${ }^{14} \mathrm{C}$. This is true for the results of Kohl et al. (1978), Rao et al. (1994), Michel et al. (1996), and Fink et al. (1998) compared to the ${ }^{14} \mathrm{C}$ work of Jull et al. (1998a).

The last 300,000 yr using ${ }^{81} \mathrm{Kr},{ }^{41} \mathrm{Ca}$ and ${ }^{14} \mathrm{C}$ studies. The radionuclide ${ }^{81} \mathrm{Kr}$ was measured in 68815 for $\mathrm{E}>60 \mathrm{MeV}$, by Reedy and Marti (1991), who derived a higher $\mathrm{J}_{10}$ that discussed in the previous section. Together with ${ }^{41} \mathrm{Ca}$ (Fink et al. 1998) data on 74275, this appears to be in better agreement with the ${ }^{14} \mathrm{C}$ data from Jull et al. (1998) than the longer-lived nuclides. Some uncertainties in cross sections remain for those two radionuclides. Klein et al. (1990) examined ${ }^{41} \mathrm{Ca}$ in rock 74275 and calculated an SCR flux of 120 protons $/ \mathrm{cm}^{2} / \mathrm{s}$ but with a low $\mathrm{R}_{0}$ of about $70 \mathrm{MV}$. Recent calculations which fitted the ${ }^{41} \mathrm{Ca}$ measurements on 74275 suggested a $\mathrm{J}_{10}$, of $\sim 200$ protons $/ \mathrm{cm}^{2} / \mathrm{s}$ and $\mathrm{R}_{0}$ of about $80 \mathrm{MV}$ should give a good fit (Fink et al. 1998). In addition, the work of Fink et al. (1998) shows a higher flux than the longer-lived nuclides and confirms the suggestion of enhanced SCR fluxes in the last $\sim 100$ to $200 \mathrm{kyr}$. So far, ${ }^{36} \mathrm{Cl}$ has not proved useful for lunar studies. Short-lived radioisotopes ${ }^{22} \mathrm{Na}$ and ${ }^{55} \mathrm{Fe}$ also show higher estimated solar-proton fluxes, as these nuclides are greatly affected by the very high solar activity in the decade immediately before the recovery of the Apollo samples (Reedy 1977). Indeed, we could state that all values of $J_{10}$ and $R_{0}$ estimated for all radionuclides are within the wide observed range of spacecraft measurements. Spacecraft results depend strongly on the solar cycle and show variations from $63 \mathrm{p} / \mathrm{cm}^{2} / \mathrm{s}\left(\mathrm{R}_{0}=40 \mathrm{MV}\right)$ to $312 \mathrm{p} / \mathrm{cm}^{2} / \mathrm{s}$ $\left(\mathrm{R}_{0} \sim 70 \mathrm{MV}\right)$, and have been discussed in detail by Reedy $(1980,1996)$ and Goswami et al. (1988).

\section{Implantation Effects}

Jull et al. (1995b, 2000a) studied an apparent surface enrichment of ${ }^{14} \mathrm{C}$, especially in lunar soil grains. The flux of $\mathrm{H}$ from the solar wind of $\sim 2 \times 10^{8} \mathrm{H} / \mathrm{cm}^{2} / \mathrm{s}$. In order to compare the flux of implanted ${ }^{14} \mathrm{C}$ with $\mathrm{H}$ we need to be able to estimate the surface area of the grains. The limits for ${ }^{14} \mathrm{C} /$ $\mathrm{H}$ estimated by Jull et al. (2000a) were $\sim 0.4$ to $0.8 \times 10^{-14}$, which was based on studies on grain-size separates of Apollo 11 soils and also Apollo 16 soil 64501. A deep soil sample collected from Apollo 17 was used as a control. The quoted ratio is lower than the ratio of 2.2 to $3.5 \times 10^{-14}$ for the same value previously reported by Jull et al. (1995b) based on etchings of bulk 10084 soil and also soils 73221, 73241, and 73261, from the Apollo 17 trench soils. The original study of Fireman 
(1977) measured similar surface enrichments of ${ }^{14} \mathrm{C}$ to Jull et al. (1995b), but estimated a much higher ratio of ${ }^{14} \mathrm{C} / \mathrm{H}$ of $\sim 10^{-11}$, due to different assumptions about the surface areas of the samples.

\section{Other Information from ${ }^{14} \mathrm{C}$ in Lunar Soil Cores}

Work on lunar core 15001-8 and rock 68815 (Jull et al. 1998) suggest a possible enhancement in the SCR flux in the time scale integrated by ${ }^{14} \mathrm{C}$. The very surface of lunar rocks and soil could also be affected by implantation of particles directly from the Sun, from the solar wind or solar flare events. Recent data (Nishiizumi et al. 1997) suggest the very surface layer might have be implanted with solar ${ }^{14} \mathrm{C}$ and perhaps some ${ }^{10} \mathrm{Be}$. Recently, further experiments on lunar soils (Jull et al. 2000a) confirm the existence of such a component, but raised new questions about whether this could indeed be of solar-wind origin.

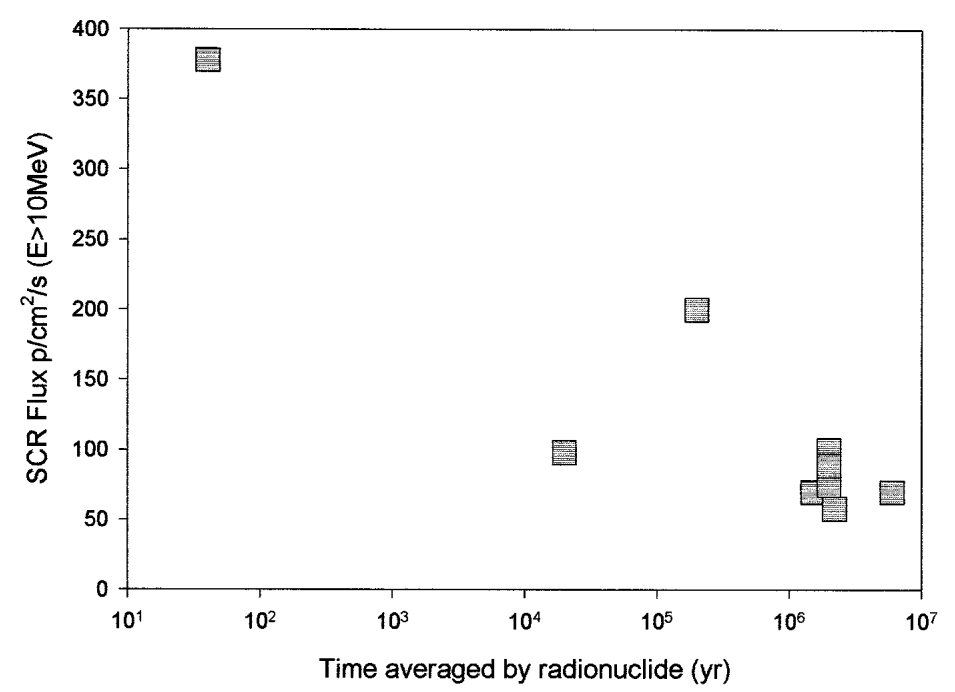

Figure 4 Solar-proton spectral parameters and $4 \pi$ integral fluxes $\left(\mathrm{p} / \mathrm{cm}^{2} / \mathrm{s}\right)$ above 10 $\mathrm{MeV}$, determined from radionuclides in lunar samples

\section{METEORITE STUDIES AND TERRESTRIAL AGES}

Meteorites fall equally all over the world and can be recovered from all parts of the globe (Halliday et al. 1989). The infall rate has been described as a function of mass where

$$
\log \mathrm{N}=\mathrm{a} \log \mathrm{M}+\mathrm{b},
$$

and where $\mathrm{N}$ is the number of meteorites which fall per $10^{6} \mathrm{~km}^{2}$ per year, $>$ mass $\mathrm{M}$ in grams. Halliday et al. (1989) determined the constants $a$ and $b$ to be -0.49 and -2.41 for $\mathrm{M}<1030 \mathrm{~g}$, and -0.82 and -3.41 for $M>1030 \mathrm{~g}$, based on observations of meteoroids. This would result in an infall rate of M>10 g of 83 events per $10^{6} \mathrm{~km}^{2} / \mathrm{yr}$, or roughly one event per $\mathrm{km}^{2}$ in $10,000 \mathrm{yr}$.

The arid and polar regions of the world appear to be the best locations for storage of meteorites, where they can survive for long periods of time in such environments (Nishio and Annexstad 1980; Nishiizumi et al. 1989; Jull et al. 1990, 1993a, 1998b, 2000b). Large numbers of meteorites have been recovered from the arid and semi-arid regions of North Africa, Arabia, North America and Western Australia. One of the first recognized areas for collections of meteorites was Roosevelt 
County, New Mexico (Scott et al. 1986; Sipiera et al. 1987). The Nullarbor region of Australia and the northern Sahara Desert in Africa are also wonderful sources of meteorites (Wlotzka et al. 1995; Bevan et al. 1998; Schultz et al. 1998). Searches have been undertaken recently in the Namib desert and dry lakes in California, and less explored areas such as the remote deserts of southern Africa and South America may yet yield many more meteorites. The cold desert of Antarctica is also a large store of meteorites. Beginning in 1969, Japanese researchers recovered a number of meteorites from Antarctica. They have continued to recover meteorites annually. In 1976, Cassidy and Olsen undertook an expedition to Antarctica to recover meteorites from the Allan Hills blue icefield, located in easy range of the US base at McMurdo. This program has since developed into the US Antarctic Search for Meteorites (ANSMET), and over 17,400 meteorites have been recovered from Antarctica, approximately equally divided between US and Japanese collections (Grady 2000). For comparison, the number of meteorites recovered (Grady 2000) from deserts are 1508 for the Sahara Desert, and $>280$ for Nullarbor.

The study of the terrestrial ages of these meteorites is of great utility, as it gives us information concerning the storage and weathering of meteorites and the study of fall times and terrestrial age. The most useful for many meteorite collection areas is ${ }^{14} \mathrm{C}\left(\mathrm{t}_{1 / 2}=5730 \mathrm{yr}\right)$, as summarized by Jull et al. (1990, 1993, 1998).

Early measurements by Suess and Wänke (1962) and Goel and Kohman (1962) on large meteorite samples (10-100 g) were made by ${ }^{14} \mathrm{C}$ decay counting. Later, Boeckl (1972) used ${ }^{14} \mathrm{C}$ to estimate terrestrial ages of some meteorites found in the central and southwestern USA, using $\sim 10 \mathrm{~g}$ samples. Fireman (1978) and Kigoshi and Matsuda (1986) made some measurements on Antarctic meteorites using similar methods. The first measurements which used AMS for ${ }^{14} \mathrm{C}$ terrestrial ages of Antarctic meteorites were by Brown et al. (1984). Subsequently, AMS has been almost exclusively used for ${ }^{14} \mathrm{C}$ terrestrial age measurements using smaller sample sizes $(0.1-0.7 \mathrm{~g})$, mainly by the Arizona group, summarized by Jull et al. (1984, 1989b, 1990, 1993a, 1993b, 1994, 1995a). Some other measurements were done at Toronto, by Beukens et al. (1998) and Cresswell et al. (1993), and by a German-Swiss consortium (Neupert et al. 1997; Stelzner et al. 1999). Longer-lived isotopes like ${ }^{81} \mathrm{Kr}$ (Freundel et al. 1986; Miura et al. 1993) and ${ }^{36} \mathrm{Cl}$ (Nishiizumi et al. 1989) can also be used to determine longer terrestrial ages. This gives us information beyond the useful range of ${ }^{14} \mathrm{C}$ of about 40,000 years. In the case of samples at the limit of ${ }^{14} \mathrm{C}$ age determination, we can sometimes place upper limits on their age by a lower limit determined by the ${ }^{36} \mathrm{Cl}$ age.

\section{Production Rate of ${ }^{14} \mathrm{C}$ and Interpretation of ${ }^{14} \mathrm{C}$ Terrestrial Ages}

Jull et al. (1994) and Wieler et al. (1996) have discussed the variation in ${ }^{14} \mathrm{C}$ production rate at different depths in meteorites of different sizes. Recent falls generally show activities of ${ }^{14} \mathrm{C}$ equivalent to a production rate of 38-58 atoms/min $/ \mathrm{kg}$ (as shown in Table 3). Wieler et al. (1996) showed calculations for meteorites of preatmospheric radii from 20 to $45 \mathrm{~cm}$ where the saturated activity (or production rate) should vary from about 38 to $52 \mathrm{dpm} / \mathrm{kg}$ for an $\mathrm{H}$ chondrite. Smaller objects have lower production rates of ${ }^{14} \mathrm{C}$. In Figure 1, we have shown the expected production rates for a sample recovered from a given depth for meteorites of H-chondrite composition of different sizes (Wieler et al. 1996). Measurements on the Knyahinya L-chondrite $(\mathrm{R}=45 \mathrm{~cm})$ gave values of 37 at the surface to $58 \mathrm{dpm} /$ $\mathrm{kg}$ at the center of the meteorite. Nearly all ${ }^{14} \mathrm{C}$ is produced from spallation of oxygen, with only about $3 \%$ produced from Si (Sisterson et al. 1994). Hence, normalization of the saturated activity observed to the oxygen content works well. We estimated the saturated activity for a given class of meteorite by normalizing the mean value of the ${ }^{14} \mathrm{C}$ content of Bruderheim $(51.1 \mathrm{dpm} / \mathrm{kg})$ to the oxygen content of the meteorite determined from bulk chemistry or from average compositions (Mason 
1979). The scatter in measurements on saturated falls suggests that an uncertainty of $\pm 15 \%$ should be included in estimates of the terrestrial age to account for uncompensated shielding or depth effects, as well as experimental uncertainty (Jull et al. 1993a). This variation is confirmed by the study of the depth dependence of ${ }^{14} \mathrm{C}$ in the chondrite Knyahinya (Jull et al. 1994), which has an estimated preatmospheric radius (R) of $45 \mathrm{~cm}$. Some measured ${ }^{14} \mathrm{C}$ activities from known meteorite falls are given in Table 3. Because many of the meteorites collected from Antarctica are small, $<100 \mathrm{~g}$, compared to other finds, these require additional criteria to determine the production rate of ${ }^{14} \mathrm{C}$. This information is not available in all cases, but we use rare gas and other radioisotope (e.g. ${ }^{26} \mathrm{Al}$ and ${ }^{10} \mathrm{Be}$ ) data to verify that the meteorite appears to have been irradiated as a body with a radius of $20-50 \mathrm{~cm}$. We can also use ${ }^{22} \mathrm{Ne} /{ }^{21} \mathrm{Ne}$ ratios to estimate the shielding depth of the sample in a meteoroid, Schultz et al. (1996) have summarized the available Ne isotopic data. For apparently smaller objects, a lower saturated activity should be used. In many cases where we do not have sufficient information to make this determination, we will quote the result for the standard values listed in Table 1 . We calculated the ${ }^{14} \mathrm{C}$ activities in dpm/kg and the terrestrial ages as described by Jull et al. (1993a).

Table 3 Saturated activities measured in recently fallen meteorites

\begin{tabular}{llccl}
\hline Meteorite & Type & Year of fall & ${ }^{14} \mathrm{C}(\mathrm{dpm} / \mathrm{kg})$ & Reference \\
\hline Bruderheim & L6 & 1962 & $51 \pm 2$ & Jull et al. (1993a) \\
Dhurumsala & LL6 & 1860 & $55.7 \pm 2.3$ & Stelzner et al (1999) \\
Holbrook & H6 & 1912 & $44 \pm 1$ & Jull et al. (1998b) \\
Peekskill & L6 & 1992 & $51.1 \pm 0.4$ & Graf et al. (1996) \\
Torino & H6 & 1992 & $42 \pm 2$ & Wieler et al. (1996) \\
Mbale & L6 & 1996 & $58.1 \pm 0.4$ & Jull et al. (1998b) \\
\hline
\end{tabular}

\section{Desert Meteorites}

${ }^{14} \mathrm{C}$ provides the best method of estimating the terrestrial age of meteorites recovered from desert environments. When combined with good recovery statistics and weathering information, we can use these ages to assist in determining infall rates (Bland et al. 1996). For the Nullarbor Plain (Western Australia) and for some other locations, we observe an approximately exponential drop-off of number of meteorites with increasing terrestrial age (Bevan et al. 1998, 1999; Jull et al. 1995b). Jull et al. (1990, 2000b), Knauer et al. (1995), Neupert (1996), Neupert et al. (1997), Stelzner et al. (1999), and Wlotzka et al. (1995) have reported on terrestrial ages of meteorites from the Sahara desert in Libya and Algeria, which show similar trends. Different climatic regimes and local geology can affect the distribution of terrestrial ages of meteorites from areas such as the Sahara desert and Roosevelt County, as weathering occurs at different rates depending on sample chemistry and local climatic effects.

Figure 5 (Color Plate 3) shows the age distribution of meteorites from some of these locations. In general, the Nullarbor and Sahara meteorites show an approximately exponential decrease of number of finds with terrestrial age to at least $30 \mathrm{ka}$. Since weathering gradually destroys meteorites, we expect that in a given population of finds, that the resulting distribution should show some exponential dependence on age. As an example, consider a collection where meteorites fell continuously directly on the collection area. The meteorites then should eventually disintegrate and reach a steady state where the disintegration rate will match the infall rate. Therefore, the number will decrease with increasing age, and so there should be more young meteorites than older ones. This is the expected distribution based on a simple first-order model of meteorite accumulation (Freundel et al. 1986; Jull et al. 1993a). We can show an example of the case of the Western Australian meteorites. 
Here, few meteorites beyond the range of ${ }^{14} \mathrm{C}$ are observed and this profile shows the simple decay model for meteorite ages. Due to other effects, at many sites this simple relationship is not always observed. Many stony meteorites can survive in desert environments for long periods (Jull et al. 1990, 1995b; Bland et al. 1998).

In a new approach to the question of meteorite survival and weathering, Bland et al. (1998) compared the terrestrial ages of many meteorites with the degrees of weathering observed. Previous studies (e.g. Wlotzka et al. 1995) had used a petrographic weathering estimate, however, Bland et al. (1998) introduced the idea of using Mössbauer spectroscopy, where the relative amounts of Fe in different valence states could be measured. Bland et al. (1996) further showed that meteorites of different composition weather at different rates, a fact known qualitatively to many meteoriticists, but difficult to quantify. Mössbauer provides that quantitation, and Bland et al. (1996) showed that H chondrites, which contain more metallic iron, weather at faster rates than $\mathrm{L}$ chondrites. We can also therefore conclude that achondrites, mainly basaltic rocks containing no iron, would survive the longest. Indeed there is some evidence to support this assertion in the observed distribution of terrestrial ages of Antarctic meteorites. This observation is particularly important as some interesting achondrites have also been recovered from these desert regions, although the vast majority are ordinary chondrites. Those of greatest interest are those of lunar and Martian origin which have been recovered from both cold and hot deserts.

\section{${ }^{14} \mathrm{C}-{ }^{10} \mathrm{Be}$ Dating}

A limitation of using ${ }^{14} \mathrm{C}$ for terrestrial age determinations is the need to make shielding corrections if the original meteoroid was very large or small (see Figure 1). One way to make these depth estimates is by ${ }^{22} \mathrm{Ne} /{ }^{21} \mathrm{Ne}$ ratios (Cressy and Bogard 1976). We can also use the production rate of a more long-lived nuclide such as ${ }^{10} \mathrm{Be}$ to normalize the ${ }^{14} \mathrm{C}$ production rate. Since both of these radionuclides are produced by the same spallation reactions on oxygen, their production in meteorites is almost always at a constant ratio. The ${ }^{14} \mathrm{C}-{ }^{10} \mathrm{Be}$ method allows us to correct for shielding effects, the only assumption we have is that the exposure age of the meteorite is sufficient to saturate ${ }^{10} \mathrm{Be}(\mathrm{Jull}$ et al. 1999b). This exposure age can also be verified by noble-gas data. Both ${ }^{14} \mathrm{C}$ and ${ }^{10} \mathrm{Be}$ can be measured by accelerator mass spectrometry (AMS) at the NSF-Arizona AMS Laboratory. The first attempt to apply this work was by Neupert et al. $(1997,1999)$, who correlated ${ }^{14} \mathrm{C},{ }^{26} \mathrm{Al}$ and ${ }^{10} \mathrm{Be}$ in some Açfer meteorites, and used the results to estimate shielding-corrected terrestrial ages. Since both ${ }^{14} \mathrm{C}$ and ${ }^{10} \mathrm{Be}$ are produced by spallation of oxygen, their depth dependence is reasonably similar, and also the production ratio is independent of chemistry. This was demonstrated in the study of the ${ }^{14} \mathrm{C}$ and ${ }^{10} \mathrm{Be}$ depth dependence in Knyahinya, a large meteorite of some $\sim 400 \mathrm{~kg}$ that fell in the Ukraine in the 19th century (Jull et al. 1994). An excellent example of the use of the ${ }^{14} \mathrm{C}-{ }^{10} \mathrm{Be}$ method for determining terrestrial age was shown by Kring et al. (2000) for the large fall of the Gold Basin meteorites. The Gold Basin meteorite shower was apparently due to the explosion of a large bolide (H4 chondrite composition) several meters in diameter over northwestern Arizona. Thousands of fragments of this object have been recovered by Kring and co-workers as well as by private individuals. We compared the results obtained for both of these radionuclides on splits of the same samples. By normalizing the ${ }^{14} \mathrm{C}$ production rate to that of ${ }^{10} \mathrm{Be}$, we can correct for the problem of ${ }^{14} \mathrm{C}$ production at a significant depth in a large object. The terrestrial age we determined is about 15,000 years (Kring et al. 1998, 2000) in the late Pleistocene. 


\section{Antarctic Meteorites}

Jull et al. (1998b) have discussed the terrestrial ${ }^{14} \mathrm{C}$ ages of 95 meteorites collected from Antarctic blue ice fields by US scientists. A map showing locations of many of the main collection areas from which meteorites have been recovered is shown in Figure 6.

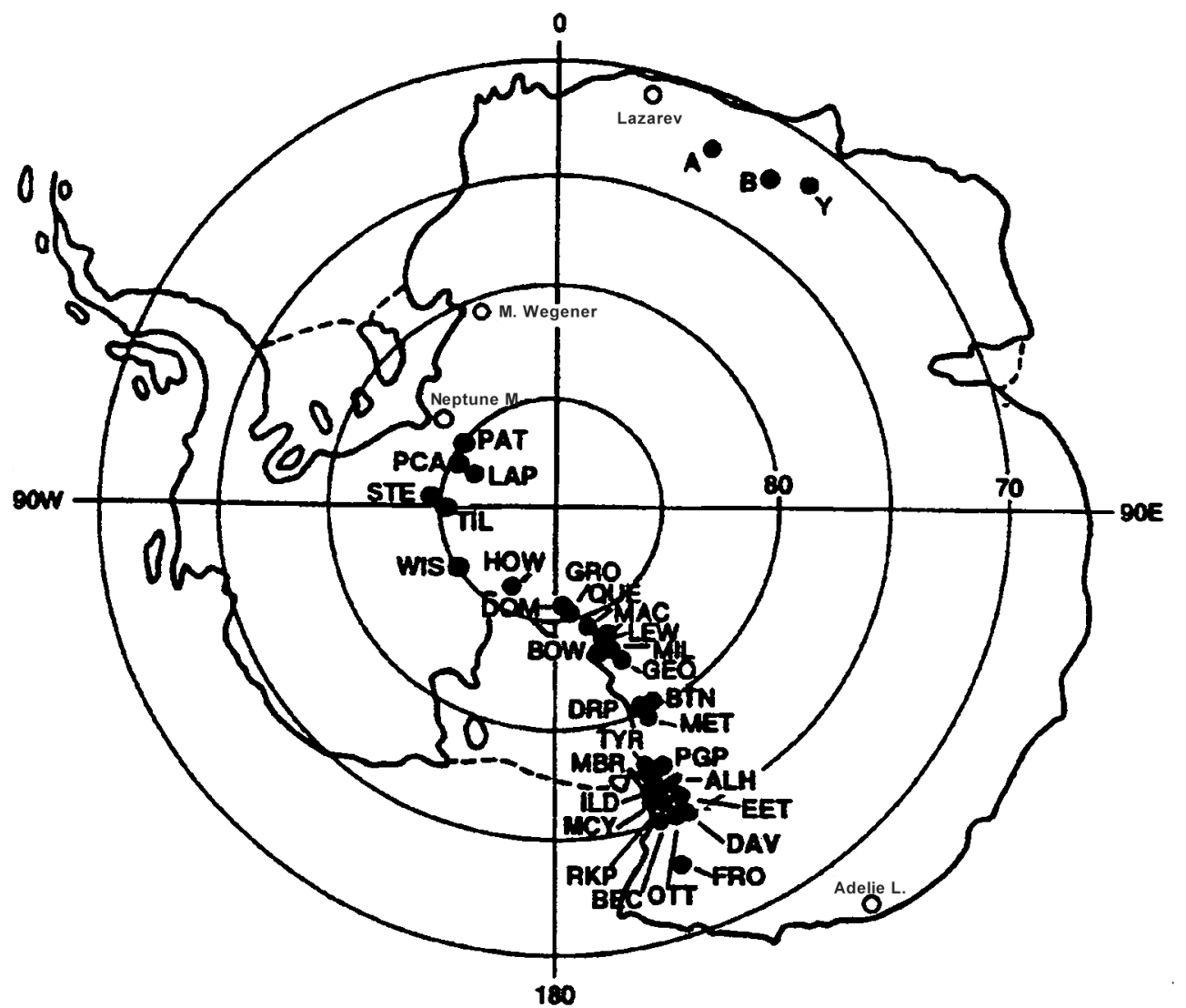

$\begin{array}{llllll}\text { A } & - & \text { Sor Rondane Mountains (Asuka) } & \text { MBR } & - & \text { Mount Baldr } \\ \text { ALH } & - & \text { Allan Hills } & \text { MET } & - & \text { Meteorite Hills } \\ \text { B } & - & \text { Belgica Mountains } & \text { MIL } & - & \text { Miller Range } \\ \text { BOW } & - & \text { Bowden Neve } & \text { OTT } & - & \text { Outpost Nunatak } \\ \text { BTN } & - & \text { Bates Nunataks } & \text { QUE } & - & \text { Queen Alexandra Range } \\ \text { DOM } & - & \text { Dominion Range } & \text { PAT } & - & \text { Patuxent Range } \\ \text { DRP } & - & \text { Derrick Peak } & \text { PCA } & - & \text { Pecora Escarpment } \\ \text { EET } & - & \text { Elephant Moraine } & \text { PGP } & - & \text { Purgatory Peak } \\ \text { GEO } & - & \text { Geologists Range } & \text { RKP } & - & \text { Reckling Peak } \\ \text { GRO } & - & \text { Grosvenor Mountains } & \text { STE } & - & \text { Stewart Hills } \\ \text { HOW } & - & \text { Mt. Howe } & \text { TIL } & - & \text { Thiel Mountains } \\ \text { ILD } & - & \text { Inland Forts } & \text { TYR } & - & \text { Taylor Glacier } \\ \text { LAP } & - & \text { LaPaz Ice Field } & \text { WIS } & - & \text { Wisconsin Range } \\ \text { LEW } & - & \text { Lewis Cliff } & \text { Y } & - & \text { Yamato Mountains } \\ \text { MAC } & - & \text { MacAlpine Hills } & & & \end{array}$

Figure 6 Map of Antarctica, showing recovery locations of meteorites. Adapted from Antarctic Meteorite Newsletter. 
Because of low storage temperatures, we expect Antarctic meteorites to be stored for long periods of time in or on the ice. This is certainly confirmed by the results, which can easily be compared to the age distributions for non-polar sites and show longer residence times than observed in warmer desert environments. In Antarctica, we observe samples both within the range of ${ }^{14} \mathrm{C}$ dating, up to $40-50 \mathrm{ka}$, and beyond. Nishiizumi et al. (1989), Cresswell et al. (1993), Jull et al. (1993b), and Michlovich et al. (1995) have shown that the age distributions of meteorites at the different Allan Hills icefields and Yamato collection sites in Antarctica can be very different. Nishiizumi et al. (1989) reported that many meteorites from the Allan Hills Main Icefield have long terrestrial ages, as determined by ${ }^{36} \mathrm{Cl}$ $\left(\mathrm{t}_{1 / 2}=301,000 \mathrm{yr}\right)$. Indeed, two meteorites have been recovered, an H-chondrite from Allan Hills (ALH88019) and an L-chondrites from Lewis Cliff (LEW86360) which have very long terrestrial ages in excess of $2 \mathrm{Ma}$ (Sherer et al. 1997; Welten et al. 1997). The largest single meteorite (with a terrestrial age $>30 \mathrm{ka}$ ) is the $100 \mathrm{~kg} \mathrm{H} 5$ meteorite LEW 85320 (Figure 8, in Color Plate 4).

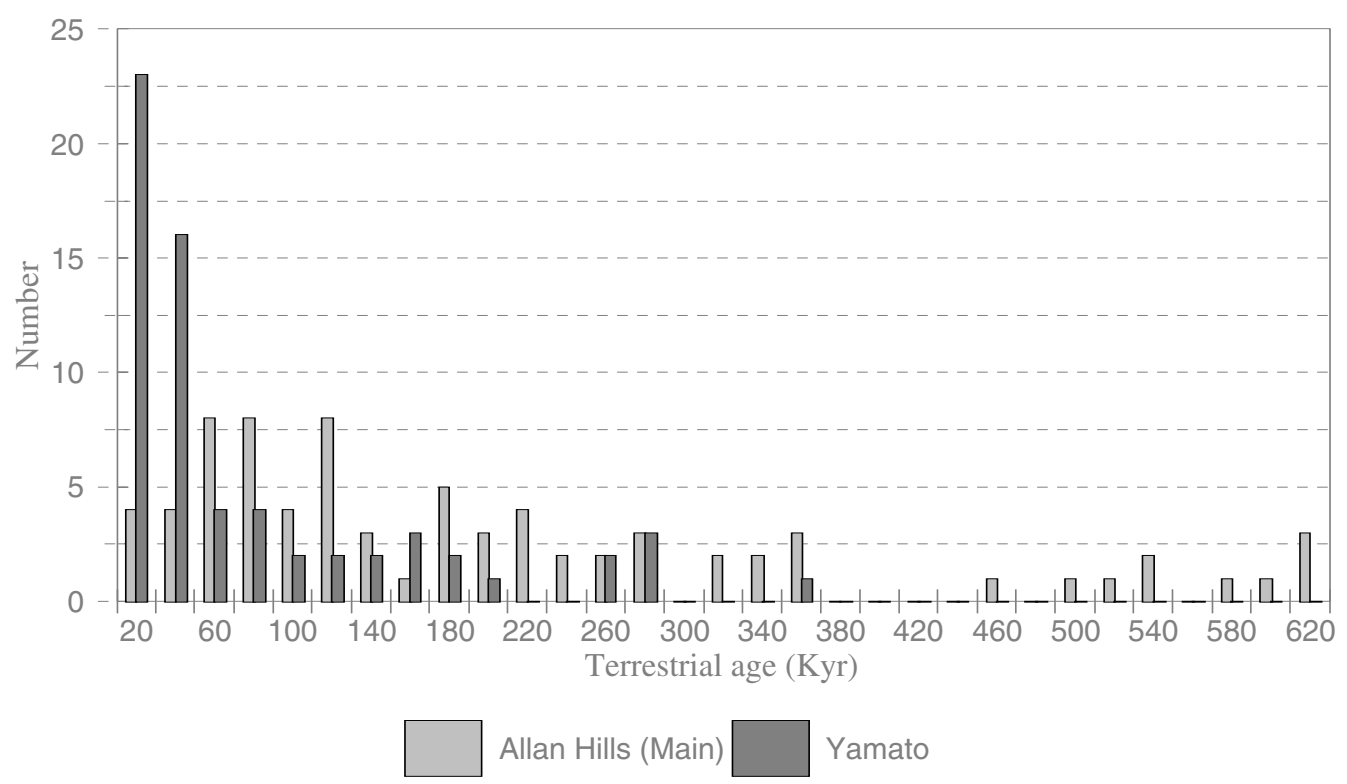

Figure 7 Terrestrial age distributions of meteorites from the Allan Hills main icefield and the Yamato site. References cited in text.

Nishiizumi et al. (1989) summarized data on 67 meteorites from the Allan Hills Main Icefield, and they found most gave ${ }^{36} \mathrm{Cl}$ terrestrial ages of chondrites of $>100 \mathrm{ka}$, and up to $500 \mathrm{ka}$ in a few cases. In Figure 7, we show a summary of terrestrial ages determined by ${ }^{14} \mathrm{C},{ }^{36} \mathrm{Cl}$ and ${ }^{81} \mathrm{Kr}$ for meteorites from this icefield and also the Japanese Yamato site. Twenty Allan Hills main meteorites $(\sim 30 \%)$ were $<70 \mathrm{ka}$, and from ${ }^{14} \mathrm{C}$, we found only five meteorites out of the 27 meteorites analyzed for ${ }^{14} \mathrm{C}$ were $<25 \mathrm{ka}$. The long terrestrial ages observed for the Allan Hills Main Icefield meteorites are normally explained by transport of the meteorites in flowing ice over large distances (Drewry 1985; Nishio and Annexstad 1980). By contrast, samples from other areas such as the Far Western Icefield (Figure 9, in Color Plate 5) and ${ }^{14} \mathrm{C}$ ages from the Yamato site (Figure 10) show significantly younger population of meteorites. At these locations, most of the samples date within the last $40 \mathrm{ka}$, although the Japanese Yamato site does show a large range of terrestrial ages, with several meteorites of terrestrial age $>200 \mathrm{ka}$ (Nishiizumi et al. 1989; Michlovich et al. 1995). 
In addition, some much older ${ }^{81} \mathrm{Kr}$ ages on one class of achondrite meteorites (eucrites) up to 300 ka have been observed (Miura et al. 1993). This may indicate a special population group more resistant to weathering, or whether this is due to some uncertainties in the ${ }^{81} \mathrm{Kr}$ production rate (cf. Reedy and Marti 1991).

In the case of the Allan Hills Far Western icefield there are few meteorites with less than saturated ${ }^{36} \mathrm{Cl}$ (Nishiizumi et al. 1989), indicating short terrestrial ages consistent with the observation of significant levels of ${ }^{14} \mathrm{C}$ in most samples. These results are shown in Figure 9. We suppose meteorites at sites like the far Western icefield or Yamato cannot have been transported any significant distance in the ice, and most likely fell at the location where they were recovered. When pairing is also taken into account, these results allow us to deduce that the distribution of meteorite terrestrial ages can be related to ice flow patterns in the Allan Hills region.

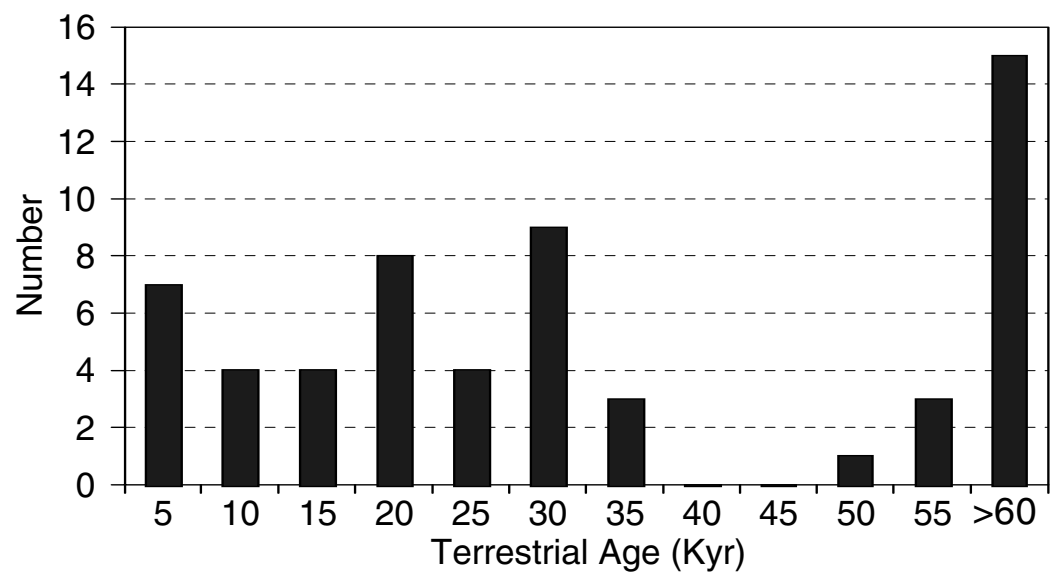

Figure 10 Terrestrial ages of meteorites from the Yamato site studied by ${ }^{14} \mathrm{C}$

We can summarize the age distributions from different icefield by listing the number with terrestrial ages $<25 \mathrm{ka}$, and categorize sites by the number of such younger falls. This allows us to order icefields in terms of number of falls $<25 \mathrm{ka}$ as follows, based on ${ }^{14} \mathrm{C}$ ages only (results are taken from Jull et al. (1993b, 1998b, 1999a); Cresswell et al. (1993); Michlovich et al. (1995), and other unpublished results from our laboratory). By contrast, the results for some desert meteorite collection areas show higher values, as seen in Table 4.

Table 4 Percentage of meteorites recovered from different locations with terrestrial ages $<25,000 \mathrm{yr}$

\begin{tabular}{lc}
\hline Location & Percentage \\
\hline Acfer, Algeria & 92 \\
Roosevelt County, New Mexico, USA & 45 \\
Far Western Icefield, Allan Hills, Antarctica & 65 \\
Yamato Mountains, Antarctica & 50 \\
Middle Western Icefield, Allan Hills, Antarctica & 30 \\
Elephant Moraine, Antarctica & 28 \\
Allan Hills Main Icefield, Antarctica & 7 \\
\hline
\end{tabular}


Many Antarctic meteorites are clearly fragments of the same fall. Indeed, 2 very large shower falls, one of an H5 chondrite at Lewis Cliffs (Figure 8, in Color Plate 4) and another of an LL5 chondrite at Queen Alexandra Range, are well documented in the US Antarctic collection. Lindstrom and Score (1994) used statistical arguments to estimate that pairing might reduce the number of discrete Antarctic falls by as much as a factor of 2 to 6 . They also suggested the frequent number of ordinary chondrites in some localities could indicate a pairing factor of as high as 5 for these meteorites. These estimates appear too high to be consistent with the terrestrial-age data available on the samples studied. However, it is possible the terrestrial-age results may have some selection bias against paired meteorites. If the high pairing were the case, any estimates of infall rates would be too high, as our calculations of infall rates rely on an estimate of the total number of meteorites collected in our to scale our observed age distributions to the whole population. We can compare the estimates of infall rate from different areas and the results summarized by Bland et al. (1996) in Table 5. Here we can see that the estimates from Allan Hills are not in disagreement with other estimates. It would be difficult to make such infall-rate estimates without any information on the fall times (terrestrial ages of the meteorites) and this demonstrates the utility of this information.

Table 5 Estimates of weathering and infall rates

\begin{tabular}{lccl}
\hline Location & $\begin{array}{c}\lambda \\
\left(\mathrm{ka}^{-1}\right)\end{array}$ & $\begin{array}{c}\mathrm{N}(>10 \mathrm{~g}) \\
\left(10^{6} \mathrm{~km}^{2} \mathrm{yr}^{-1}\right)\end{array}$ & Reference \\
\hline Meteor observations & & 83 & Halliday et al. (1989) \\
Roosevelt County & 0.032 & 116 & Bland et al. (1996); Jull et al. (1991) \\
Nullarbor Plain & 0.024 & 36 & Bland et al. (1996) \\
Sahara Desert & 0.011 & $95-431$ & Bland et al. (1996) \\
Allan Hills Main & & $\sim 50$ & Jull et al. (1998b) \\
Allan Hills Far Western & 0.017 & 53 & Jull et al. (1998b) \\
\hline
\end{tabular}

\section{USING ${ }^{14} \mathrm{C}$ TO TRACE THE ORIGIN OF ORGANIC MATERIALS IN MARTIAN METEORITES}

McKay et al. (1996) reported evidence suggesting the possibility of biogenic fossils in the orthopyroxenite meteorite, Allan Hills 84001. This discovery ignited a debate on the question of whether early Mars could have supported life. This meteorite, together with Elephant Moraine 79001 and other Martian (sometimes referred to as SNC) meteorites, form a class of rare meteorites called achondrites. These are basically igneous rocks and were apparently ejected from the surface of Mars (McSween 1994). The work of McKay et al. (1996) has stimulated much discussion as to the nature and origin of organic material in ALH 84001 and EETA 79001 in particular, and other Martian meteorites in general. Important clues to the origin of the organic material can be obtained from the amounts of ${ }^{14} \mathrm{C}$ and the relative amounts of ${ }^{13} \mathrm{C} /{ }^{12} \mathrm{C}$.

We have studied the isotopic ratios $\delta^{13} \mathrm{C}, \delta^{18} \mathrm{O}$ and the ${ }^{14} \mathrm{C}$ compositions of $\mathrm{CO}_{2}$ released from carbonates (Jull et al. 1997) and organic compounds in these meteorites (Jull et al. 1998c). We can use ${ }^{14} \mathrm{C}$ as well as their stable isotopic composition $\left(\delta^{13} \mathrm{C}\right)$ to identify their origin. Small amounts of $\mathrm{CO}_{2}$ produced by combustion in oxygen is let into a mass spectrometer to determined $\delta^{13} \mathrm{C}$. The gas is then recovered from the mass spectrometer using liquid nitrogen to free out the gas into a glass ampoule and the gas in transferred to another system. Here, the sample is reduced to graphite and the ${ }^{14} \mathrm{C}$ content of the sample is determined by AMS. Terrestrial organic material, which mainly originates from biogenic activity, has levels of ${ }^{14} \mathrm{C}$ consistent with the time since removal from equilibrium with the terrestrial biosphere or atmosphere, as discussed by Jull et al. (1998c, 1999b). 
We can also estimate the effects on organic material exposed to radiation in space, might sometimes contain excess ${ }^{14} \mathrm{C}$ produced by the action of cosmic rays. We know that meteorites are bombarded by cosmic rays in space. The ${ }^{14} \mathrm{C}$ can be produced only by thermal neutrons on ${ }^{14} \mathrm{~N}$, or to a much lesser extent by neutron capture on ${ }^{13} \mathrm{C}$. As we know that all samples of these meteorites so far recovered were irradiated as small objects in space with only trace water content, very few cosmicray generated neutrons can have been produced. Spergel et al. (1986) had shown that for objects of radius less than $\sim 50 \mathrm{~g} / \mathrm{cm}^{2}$ (about $150 \mathrm{~cm}$ in a rock, or approximately $19 \mathrm{~kg}$ in mass) that the cosmic ray induced thermal neutron flux is extremely small and neutron products are not detectable. For these meteorites, ALH84001, Nakhla and EETA79001 were much smaller than this size $(2.1,10$, and $7.9 \mathrm{~kg}$ recovered mass, respectively), and thus the thermal neutron flux would be even, hence we can eliminate this production of ${ }^{14} \mathrm{C}$ in the organic components of these Martian meteorites.

We performed stepped heating experiments on several sample of these Martian meteorites. For EETA79001, the intermediate temperature $\left(\sim 400-600^{\circ} \mathrm{C}\right)$ fractions reveal that the carbonate mineral component of EETA79001 has exchanged with terrestrial carbon dioxide to some extent, because we observe ${ }^{14} \mathrm{C}$ in these fractions. However, the carbonate fraction of ALH84001 is low in ${ }^{14} \mathrm{C}$ and this is consistent with an extraterrestrial origin. The large difference in both ${ }^{14} \mathrm{C}$ and $\delta^{13} \mathrm{C}$ measurements of organic and carbonate fractions of ALH84001 indicates that it is extremely unlikely that they could have formed from a common reservoir of carbon. Also, we know from the work of Nyquist et al. (1999) that the carbonates likely formed 3.9 Gyr ago. Hence, if the organic material and carbonate coexist and were formed from a common reservoir, we would have to find a mechanism to produce the large differences in $\delta^{13} \mathrm{C}$. If we only had the $\delta^{13} \mathrm{C}$, we know that isotopic fractionation between methane and carbon dioxide can be large (about 70\%o) at low temperatures can occur, but only under certain conditions. This would require that the ${ }^{14} \mathrm{C}$ concentration (which is corrected for isotopic effects) in both phases be the same. Thus, the ${ }^{14} \mathrm{C}$ "label" is very important and it tells us if these phases have some terrestrial contaminants which were either biogenic or at some time in equilibrium with the atmosphere. ${ }^{14} \mathrm{C}$ measurements reveals that the carbonate $\mathrm{CO}_{2}$ is low in ${ }^{14} \mathrm{C}$. The fraction 500-600 ${ }^{\circ} \mathrm{C}$ appears to be the purest carbonate release, with $\mathrm{Fm}\left({ }^{14} \mathrm{C}\right)<0.04$. This is consistent with previous work on carbonates with $\delta^{13} \mathrm{C}$ of $+40 \%$ o (Jull et al. 1997) and our estimated ${ }^{14} \mathrm{C}$ composition of carbonates irradiated in space. This also supports the preterrestrial nature of these ALH carbonates, which is also clear from their petrology (Mittlefehldt et al. 1994).

We also combusted of a sample of ALH84001 which had been etched with phosphoric acid to remove any carbonates (Jull et al. 1998c). The carbon dioxide released by acid etching gave $337 \mathrm{ppm}$ carbon as carbonate, with $\delta^{13} \mathrm{C}$ of $+37.10 \pm 0.01 \%$. This yield can be favorably compared to the $367 \mathrm{ppm}$ carbon released in the previous stepped combustion of ALH84001 between 430 and $600{ }^{\circ} \mathrm{C}$. So, this confirms that our temperature fractions give similar amounts of carbonate in 430 $600{ }^{\circ} \mathrm{C}$. These results are shown in Figure 11.

The results confirm the general trend already observed, that the organic material combusting between $75-400{ }^{\circ} \mathrm{C}$ is isotopically light, -31.9 to $-25 \%$ and the fraction of modern carbon in these different steps is $23-40 \%$ modern (equivalent to $7400-11,900 \mathrm{yr}$ old). Above $400{ }^{\circ} \mathrm{C}$, our study indicates that the ${ }^{13} \mathrm{C}$-enriched carbonate is removed by acid etching, $\delta^{13} \mathrm{C}$ values of -14.7 and $-8.1 \%$ and low ${ }^{14} \mathrm{C}$ suggest the possible presence of another component. This small component appears to be an indigenous organic material combusting at higher temperature. This is likely some higher molecular weight material. Interestingly, Gilmour and Pillinger (1994) found similar $\delta^{13} \mathrm{C}$ values for polymeric material from the Murchison carbonaceous chondrite. This material would then be extraterrestrial, but not biogenic in origin. 

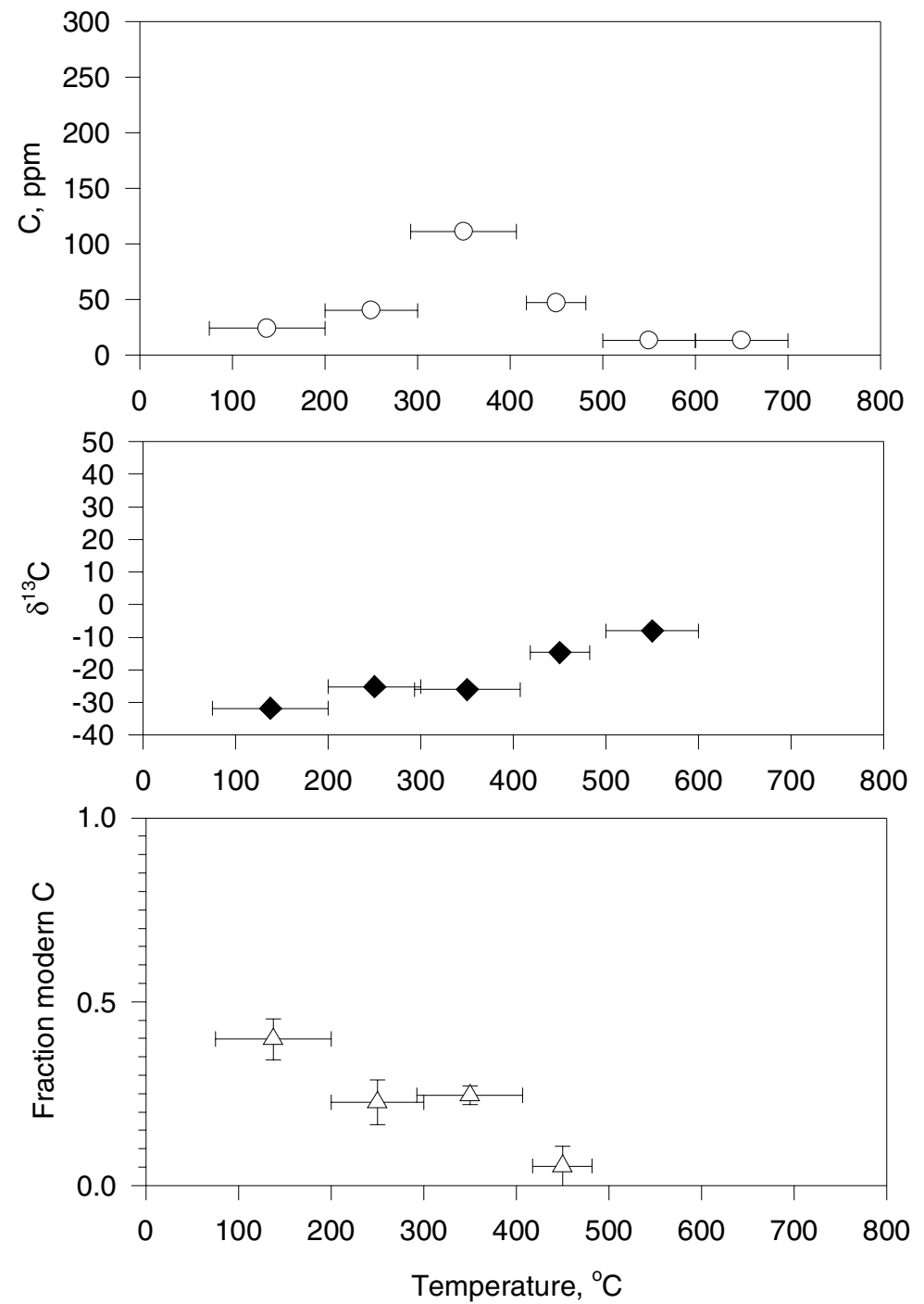

Figure 11 Stepped-combustion studies of an acid-etched residue of the Allan Hills 84001 Mars meteorite. Low-temperature steps indicate the release of terrestrial contaminants containing more ${ }^{14} \mathrm{C}$. The lowest ${ }^{14} \mathrm{C}$ release occurs in the $400-500{ }^{\circ} \mathrm{C}$ step, which appears to indicate an extraterrestrial organic-like component. Adapted from Jull et al. (1998c).

McKay et al. (1996) only directly studied small portion $(\sim 1 \%)$ of the organics in the form of polycyclic aromatic hydrocarbons (PAH) in ALH 84001. The small size of this fraction precludes ${ }^{14} \mathrm{C}$ measurements on these phases. In a separate paper published in the same issue of Science as our paper, Bada et al. (1998) studied amino acids in ALH84001. They concluded that the amino acids in this meteorite were all of the left-handed variety. All amino acids used biologically on Earth are of this type. This suggests contamination also, although amino acids from non-Earth life (if they exist) might be either left or right-handed. However, they could not be an equal mixture of right and left, which would indicate an origin from non-biological processes. 
Becker et al. (1999) have recently reexamined the isotopic composition of the acid-insoluble component in ALH84001. They found that the acid-soluble component of the organics had $\delta^{13} \mathrm{C}$ of $-26 \%$, whereas the acid-insoluble component was $-15 \%$. The latter result was consistent with the $\delta^{13} \mathrm{C}$ values for the acid-resistant organic matter combusting at $400-500{ }^{\circ} \mathrm{C}$ reported by Jull et al. (1998c). Some differences in yield are apparent, Becker et al. (1999) used $1 \mathrm{~N} \mathrm{HCl}$ as opposed to the phosphoric acid used by Jull et al. (1998c).

Recently, we have also studied bulk combustions of the observed fall, Nakhla. This meteorite fell in Egypt in 1911, and was collected in that year and 1913. Studies of the bulk combustion of a sample of this meteorite stored in the Natural History Museum indicated that $~ 80 \%$ of the organic material in this meteorite is of recent terrestrial origin. Contamination for the pre-bomb period 19111950 AD ought to be $\sim 98 \%$ modern. More recent studies (discussed by Jull et al. 1999b) on a freshly cut piece of the meteorite suggest that ${ }^{14} \mathrm{C}$ could be used to demonstrate that much of the organic material was extraterrestrial, using the rationale discussed above. The organic material in Nakhla appears to be soluble in strong acids, and may have some similarities to the polymeric organic material found in carbonaceous chondrites. Obviously, more work on the isotopic composition and characterization of this material will need to be done in the future.

\section{CONCLUSION}

${ }^{14} \mathrm{C}$ and other cosmogenic radionuclides have valuable applications in the extraterrestrial as well as the terrestrial realm. Cosmic-ray production of radionuclides in space gives us important information both about the history of cosmic rays, but also about the history of meteorites after they fall to the surface of the earth, as well as their infall history.

\section{ACKNOWLEDGMENTS}

We are grateful to the National Aeronautics and Space Administration (NASA) for provision of lunar samples, and to the Meteorite Working Group (USA), Smithsonian Institution, National Institute of Polar Research (Tokyo), Max-Planck-Institut für Chemie (Mainz), Western Australian Museum, and Natural History Museum (London) for provision of meteorite samples. We also acknowledge L J Toolin, A L Hatheway, L R Hewitt, T Lange, and D Reines for technical support of this work. This work was supported in part by grant NAG5-4832 from NASA and partly from grants EAR 95-08413 and EAR97-30699 from the National Science Foundation. We are also grateful to support for undergraduate research work by S E Klandrud, S Cloudt, and E Cielaszyk from the Arizona Space Grant College Consortium.

\section{REFERENCES}

Armstrong TW, Alsmiller RG Jr. 1971. Calculation of cosmogenic radionuclides in the Moon and comparison with Apollo measurements. Proceedings of the 2nd Lunar Science Conference: 1729-45.

Bada JL, Glavin DP, McDonald GD, Becker L. 1998. A search for endogenous amino acids in the Martian meteorite, ALH84001. Science 279:362-5.

Becker L, Popp B, Rust T, Bada JL. 1999. The origin of organic matter in the Martian meteorite ALH84001. Earth and Planetary Science Letters 167:71-9.

Begemann F, Born W, Palme H, Vilcsek E, Wänke H. 1972. Cosmic-ray produced radioisotopes in Apollo 12 and Apollo 14 samples. Proceedings of the $3 \mathrm{rd} \mathrm{Lu-}$ nar Science Conference: 1693-702.

Beukens RP, Rucklidge JC, Miura Y. $1988 .{ }^{14} \mathrm{C}$ ages of Yamato and Allan Hills meteorites. Proceedings of the NIPR Symposium on Antarctic Meteorites 1:224-30.

Bevan AWR, Bland PA, Jull AJT. 1998. Meteorite flux on the Nullarbor Region, Australia. In: Grady MM, Hutchison R, McCall GJ, Rothery DA, editors. Meteorites: flux with time and impact effects. London: Geological Society. Special Publication 140:59-73.

Bland PA, Smith TB, Jull AJT, Berry FJ, Bevan AWR, Cloudt S, Pillinger CT. 1996. The flux of meteorites to the Earth over the last 50,000 years. Monthly Notices of the Royal Astronomical Society 283:551-65. 
Bland PA, Sexton AS, Jull AJT, Bevan AWR, Berry FJ, Thornley DM, Astin TR, Britt DT, Pillinger CT. 1998. Geochimica et Cosmochimica Acta 62:3169-84.

Bodeman R, Lange H-J, Leya I, Michel R, Schiekel T, Roesel R, Herpers U, Hoffman HJ, Dittrich B, Suter M, Woelfli W. 1993. Production of residual nuclei by proton-induced reactions on $\mathrm{C}, \mathrm{N}, \mathrm{O}, \mathrm{Mg}, \mathrm{Al}$ and $\mathrm{Si}$. Nuclear Instruments and Methods in Physics Research $\mathrm{B} 82: 9-31$.

Boeckl RS. 1972. A depth profile of ${ }^{14} \mathrm{C}$ in lunar rock 12002. Earth and Planetary Science Letters 16:26972 .

Borg LE, Connelly JN, Nyquist LE, Shih CY, Wiesmann H, Reese Y. 1999. The age of the carbonates in Martian meteorites ALH84001. Science 286:90-4.

Born W. 1973. ${ }^{14} \mathrm{C}$ in Meteoriten und Mondproben und ihre Deutung durch Vergleich mit berechneten Tiefenprofilen. Doctoral thesis, Universität Mainz.

Brown RM, Andrews HR, Ball GC, Burn N, Imahori Y, Milton JCD, Fireman EL. 1984. ${ }^{14} \mathrm{C}$ content of ten meteorites measured by Tandem Accelerator Mass Spectrometry. Earth and Planetary Science Letters 67:1-8.

Cresswell RG, Miura Y, Beukens RP, Rucklidge JC. 1993. ${ }^{14} \mathrm{C}$ terrestrial ages of nine Antarctic meteorites using $\mathrm{CO}$ and $\mathrm{CO}_{2}$ temperature extractions. Proceedings of the NIPR Symposium on Antarctic Meteorites 6:381-90.

Cressy PJ Jr, Bogard DD. 1976. On the calculation of cosmic-ray exposure ages of stone meteorites. Geochimica et Cosmochimica Acta 40:749-62.

Donahue DJ, Linick TW, Jull AJT. 1990. Isotope-ratio and background corrections for accelerator mass spectrometry radiocarbon measurements. Radiocarbon 32(2): $135-42$

Drewry DJ. 1985. Entrainment, transport and concentration of meteorites in polar ice sheets. Lunar and Planetary Institute Technical Report 86-01: 37-47.

Fink D, Klein J, Middleton R, Vogt S, Herzog GF, Reedy RC. $1998 .{ }^{41} \mathrm{Ca},{ }^{26} \mathrm{Al}$, and ${ }^{10} \mathrm{Be}$ in lunar basalt 74275 and ${ }^{10} \mathrm{Be}$ in the double drive tube $74002 / 74001$. Geochimica et Cosmochimica Acta. Forthcoming.

Fireman EL. 1978. Carbon-14 in lunar soil and in meteorites. Proceedings of the 9th Lunar and Planetary Conference. 1647-54.

Fireman EL, DeFelice J, D'Amico J. 1976. The abundances of ${ }^{3} \mathrm{H}$ and ${ }^{14} \mathrm{C}$ in the solar wind. Earth and Planetary Science Letters 32:185-90.

Fireman EL, DeFelice J, D'Amico J. 1977. ${ }^{14} \mathrm{C}$ in lunar soil: temperature-release and grain-size dependence. Proceedings of the 8th Lunar Science Conference: 3749-54.

Freundel M, Schultz L, Reedy RC. 1986. Terrestrial ${ }^{81} \mathrm{Kr}-\mathrm{Kr}$ ages of Antarctic meteorites. Geochimica et Cosmochimica Acta 50:2663-73.

Gilmour I, Pillinger CT. 1994. Isotopic compositions of individual polycyclic aromatic hydrocarbons from the Murchison meteorite. Monthly Notices of the Royal
Astronomy Society 269:235-40.

Goel PS, Kohman T. 1962. Cosmogenic carbon-14 in meteorites and terrestrial ages of "finds" and craters. Science 136:875-6.

Goswami JN, McGuire RE, Reedy RC, Lal D, Jha R. 1988. Solar flare protons and alpha particles during the last three solar cycles. Journal of Geophysical Research 93:7195-7205.

Grady MM. 2000. Meteorites from cold and hot deserts: how many, how big and what sort? In: Schultz L, Franchi I, Reid A, Zolensky M, editors. Workshop on Extraterrestrial Materials from Cold and Hot Desserts. Houston: Lunar and Planetary Institute. Lunar and Planetary Institute Contribution 997:36-40.

Graf Th, Marti K, Xue S, Herzog GF, Klein J, Middleton R, Metzler K, Herd R, Brown P, Wacker JF, Jull AJT, Masarik J, Koslowsky VT, Andrews HR, Cornett RJJ, Davies WG, Greiner BF, Imahori Y, McKay JW, Milton GM, Milton JCD. 1997. Exposure history of the Peekskill (H6) meteorite. Meteoritics and Planetary Science 32:25-30.

Grossman JN. 1999. Meteoritical Bulletin Nr 83, 1999 July. Meteoritics and Planetary Science 34:A169-86

Halliday I, Blackwell AT, Griffin AA. 1989. The flux of meteorites on the Earth's surface. Meteoritics and Planetary Science 24:173-8.

Huss GR. 1990. Meteorite infall as a function of mass: Implications for the accumulation of meteorites on Antarctic ice. Meteoritics and Planetary Science 25: 41-56.

Jull AJT, Donahue DJ, Zabel TH, Fireman EL. 1984. Carbon-14 ages of Antarctic meteorites with accelerator and small-volume counting techniques. Proceedings of the 15th Lunar and Planetary Science Conference. Journal of Geophysical Research 89:C329-35.

Jull AJT, Englert PAJ, Donahue DJ, Reedy RC, Lal D. 1989a. Cosmogenic nuclide production rates: Carbon-14 from neutron spallation. Lunar and Planetary Science 20:490-1.

Jull AJT, Donahue DJ, Linick TW. 1989b. Carbon-14 activities in recently-fallen meteorites and Antarctic meteorites. Geochimica et Cosmochimica Acta 53:12951300

Jull AJT, Wlotzka F, Palme H, Donahue DJ. 1990. Distribution of terrestrial age and petrologic type of meteorites from the Libyan Desert. Geochimica et Cosmochimica Acta 54:2985-99.

Jull AJT, Wlotzka F, Donahue DJ. 1991. Terrestrial ages and petrologic type of Roosevelt County meteorites. Lunar and Planetary Science 22:665-6.Jull AJT, Donahue DJ, Reedy RC. $1992 .{ }^{14} \mathrm{C}$ depth profile in lunar rock 68815. Lunar and Planetary Science 23:63940.

Jull AJT, Donahue DJ, Cielaszyk E, Wlotzka F. 1993a. Carbon-14 terrestrial ages and weathering of 27 meteorites from the southern high plains and adjacent areas (USA). Meteoritics and Planetary Science 28:188-95. 
Jull AJT, Miura Y, Cielaszyk E, Donahue DJ, Yanai K. 1993b. AMS ${ }^{14} \mathrm{C}$ ages of Yamato achondritic meteorites. Tokyo: National Institute of Polar Research. Proceedings of the NIPR Symposium on Antarctic Meteorites 6:374-80.

Jull AJT, Donahue DJ, Reedy RC, Masarik J. 1994. Carbon-14 depth profile in the L5 chondrite Knyahinya. Meteoritics and Planetary Science 29:649-738.

Jull AJT, Bevan AWR, Cielaszyk E, Donahue DJ. 1995a Carbon-14 terrestrial ages and weathering of meteorites from the Nullarbor Plain, Western Australia. $\mathrm{Lu}$ nar and Planetary Institute Technical Report 95-02: 37-38.

Jull AJT, Lal D, Donahue DJ. 1995b. Evidence for a noncosmogenic implanted ${ }^{14} \mathrm{C}$ component in lunar samples. Earth Planetary Science Letters 136:693-702.

Jull AJT, Eastoe CJ, Cloudt S. 1997. Isotopic composition of carbonates in the SNC meteorites, Allan Hills 84001 and Zagami. Journal of Geophysical Research 102:1663-9.

Jull AJT, Cloudt S, Donahue DJ, Sisterson JM, Reedy RC, Masarik J. 1998a. ${ }^{14} \mathrm{C}$ depth profiles in Apollo 15 and 17 cores and lunar rock 68815. Geochimica et Cosmochimica Acta 62:3025-36.

Jull AJT et al. 1998b. ${ }^{14} \mathrm{C}$ terrestrial ages of meteorites from Victoria Land, Antarctica and the infall rates of meteorites. In: Grady MM et al., editors. Meteorites: flux with time and impact effects. Geol. Society of London Special Publication 140:75-91.

Jull AJT, Courtney C, Jeffrey DA, Beck JW. 1998c. Isotopic evidence for a terrestrial source of organic compounds found in Martian meteorites, Allan Hills 84001 and Elephant Moraine 79001. Science 279: 366-8.

Jull AJT, Klandrud SE, Cielaszyk E, Cloudt S. 1999a. Carbon-14 terrestrial ages of meteorites from the $\mathrm{Ya}$ mato region, Antarctica. Antarctic Meteorites XXIV. Tokyo: National Institute of Polar Research. p 62-3.

Jull AJT, Beck JW, Burr GS, Gilmour IA, Sephton MA, Pillinger CT. 1999b. Isotopic evidence for abiotic organic compounds in the Martian meteorite Nakhla. Meteoritics and Planetary Science 34. Supplement A: 60-1.

Jull AJT, Lal D, McHargue L, Burr GS, Donahue DJ. 2000a. Cosmogenic and implanted radionuclides studied by selective etching of lunar soils. Nuclear Instruments and Methods in Physics Research. Forthcoming.

Jull AJT, Bland PA, Klandrud SE, McHargue LR, Bevan AWR, Kring DA, Wlotzka F. 2000b. Using ${ }^{14} \mathrm{C}$ and ${ }^{14} \mathrm{C}-{ }^{10} \mathrm{Be}$ for terrestrial ages of desert meteorites. In: Schultz L, Franchi I, Reid A, Zolensky M, editors. Workshop on Meteorites from Cold and Hot Deserts. Houston: Lunar and Planetary Institute. Lunar and Planetary Institute Contribution 997:41-3.

Keays RR, Ganapathy R, Laul JC, Anders E, Herzog GF, Jeffrey PM. 1970. Trace elements and radioactivity in lunar rocks: implications for the meteorite infall, so- lar-wind flux and formation conditions of the Moon. Science 167:490-3.

Kigoshi K, Matsuda E. 1986. Radiocarbon datings of Yamato meteorites. Lunar and Planetary Institute Technical Report 86-01:58-60.

Klein J, Fink D, Middleton R, Vogt S, Herzog GF, Reedy RC, Sisterson JM. 1990. Average SCR flux over the last $10^{5}$ years: Inference from ${ }^{41} \mathrm{Ca}$ in lunar rock 74275. Lunar and Planetary Science 21:635-6.

Knauer M, Neupert U, Michel R, Bonani G, DittrichHannen B, Hajdas I, Ivy-Ochs S, Kubik PW, Suter M. 1995. Measurement of the long-lived radionuclides Beryllium-10, Carbon-14 and Aluminum-26 in meteorites from hot and cold deserts by accelerator mass spectrometry (AMS). Houston: Lunar and Planetary Institute. Lunar and Planetary Institute Technical Report 95-02:38-42.

Kohl CP, Murrell MT, Russ GP III, Arnold JR. 1978. Evidence for the constancy of the solar cosmic ray flux over the past ten million years: ${ }^{53} \mathrm{Mn}$ and ${ }^{26} \mathrm{Al}$ measurements. Proceedings of the 9th Lunar and Planetary Science Conference:2299-2310.

Kring DA, Jull AJT, McHargue LR, Hill DH, Cloudt S, Klandrud SE. 1998. Gold Basin meteorite strewn field: the "fossil" remnants of an asteroid that catastrophically fragmented in Earth's atmosphere. Lunar and Planetary Science 29. CD-ROM. p 1526-7.

Kring DA, Jull AJT, Bland PA. 2000. The Gold Basin strewn field, Mojave Desert, and its survival from the late Pleistocene to the present. In: Schultz L, Franchi I, Reid A, Zolensky M, editors. Workshop on extraterrestrial materials from cold and hot deserts. Houston: Lunar and Planetary Institute. Lunar and Planetary Institute Contribution 997:44-5.

Langevin Y, Arnold JR, Nishiizumi K. 1982. Lunar surface gardening processes: comparisons of model calculations with radionuclide data. Journal of Geophysical Research 87:6681-91.

Lanzerotti LJ, Reedy RC, Arnold JR. 1973. Alpha particles in solar cosmic rays over the last 80,000 years. Science 179: 1232-4.

Lindstrom MM, Score R. 1994. Populations, pairing and rare meteorites in the U.S. Antarctic meteorite collection. Lunar and Planetary Institute Technical Report 95-02:43-5.

Lingenfelter RE, Hudson HS. 1980. Solar particle fluxes and the ancient sun. In: Pepin RO, editor. The ancient Sun: fossil record in the Earth, Moon and meteorites. Pergamon Press. p 69-79.

Masarik J, Reedy RC. 1994. Effects of bulk composition on nuclide production processes in meteorites. Geochimica et Cosmochimica Acta 58:5307-17.

Mason B. 1979. Cosmochemistry, part 1. Meteorites. In: Fleischer M, editor. Data of geochemistry. 6th edition. U.S. Geological Survey Professional Paper 440-B-1.

McKay DS, Gibson EK Jr, Thomas-Keprta KL, Vali H, Romanek CS, Clemett SJ, Chillier XDF, Maechling CR, Zare RN. 1996. Search for past life on Mars: pos- 
sible relic biogenic activity in Martian meteorite ALH84001. Science 273:924-30.

McSween HY Jr. 1994. What we have learned about Mars from SNC meteorites. Meteoritics and Planetary Science 29:757-79.

Michel R, Leya I, Borges L. 1996. Production of cosmogenic nuclides in meteoroids: Accelerator experiments and model calculations to decipher the cosmic ray record in extraterrestrial matter. Nuclear Instruments and Methods in Physics Research B113:434-44.

Michlovich ES, Wolf SF, Wang MS, Vogt S, Elmore D, Lipschutz ME. 1995. Chemical studies of $\mathrm{H}$ chondrites 5. Temporal variations of sources. Journal of Geophysical Research 100:3317-33.

Miura Y, Nagao K, Fujitani T. $1993 .{ }^{81} \mathrm{Kr}$ terrestrial ages and grouping of Yamato eucrites based on noble-gas and chemical compositions. Geochimica et Cosmochimica Acta 57:1857-66.

Mittlefehldt D. 1994. ALH84001, a cumulate orthopyroxenite member of the martian meteorite clan. Meteoritics 29:214-21.

Neupert U, Michel R, Leya I, Neumann S, Schultz L, Scherer P, Bonani G, Hajdas I, Ivy-Ochs S, Kubik PW, Suter M. 1997. Ordinary chondrites from the Açfer region: a study of exposure histories. Meteoritics and Planetary Science 32:A98-9.

Nishiizumi K, Imamura M, Kohl CP, Nagai H, Kobayashi K, Yoshida K, Yamashita H, Reedy RC, Honda M, Arnold JR. 1988. ${ }^{10}$ Be profiles in lunar surface rock 68815. Proceedings of the 18th Lunar and Planetary Science Conference. p 79-85.

Nishiizumi K, Kubik PW, Elmore D, Reedy RC, Arnold JR. 1989. Cosmogenic ${ }^{36} \mathrm{Cl}$ production rates in meteorites and the lunar surface. Proceedings of the 19th Lunar and Planetary Science Conference. 305-12.

Nishiizumi K, Nagai H, Imamura M, Kobayashi K, Kubik PW, Sharma P, Wieler R, Signer P, Goswami JN, Sinha N, Reedy RC, Arnold JR. 1990. Solar cosmicray produced nuclides in the Salem meteorite. Meteoritics 25:392-3.

Nishiizumi K, Kohl CP, Arnold JR, Finkel RC, Caffee MW, Masarik J, Reedy RC. 1995. Final results of cosmogenic nuclides in lunar rock 64455. Lunar and Planetary Science 26:1055-6.

Nishiizumi K, Caffee MW, Arnold JR. 1997. ${ }^{10}$ Be from the active sun. Lunar and Planetary Science 28:10278 .

Nishio F, Annexstad JO. 1980. Studies on the ice flow in the bare ice area near the Allan Hills in Victoria Land, Antarctica. Memoirs of the National Institute of Polar Research, Tokyo. Special issue 17:1-13.

Rao MN, Garrison DH, Bogard DD, Reedy RC. 1994. Determination of the flux and energy distribution of energetic solar protons in the past 2 Myr using lunar rock 68815. Geochimica et Cosmochimica Acta 58: 4231-45.

Reedy RC. 1977. Solar proton fluxes since 1956. Proceedings of the 8th Lunar and Planetary Science Con- ference: $825-39$.

Reedy RC. 1980. Lunar radionuclide records of average solar-cosmic-ray fluxes over the last ten million years. In Pepin RO et al., editors. The ancient Sun: fossil record in the Earth, Moon and meteorites. Pergamon Press. p 365-86.

Reedy RC. 1996. Constraints on solar particle events from comparisons of recent events and million-year averages. In Balasubramaniam KS et al., editors. Solar Drivers of Interplanetary and Terrestrial Disturbances. Astronomy Society Pacific Conference Series 95:429_ 36.

Reedy RC, Arnold JR. 1972. Interactions of solar and galactic cosmic-ray particles with the Moon. Journal of Geophysical Research 77:537-55.

Reedy RC, Marti K. 1991. Solar-cosmic-ray fluxes during the last ten million years. In: Sonett $\mathrm{CP}$ et al., editors. The Sun in time. Tucson: University of Arizona Press. p 260-87.

Scherer P, Schultz L, Neupert U, Knauer M, Neumann S, Leya I, Michel R, Mokos J, Lipschutz ME, Metzler K, Suter M, Kubik PW. 1997. Allan Hills 88019: an Antarctic $\mathrm{H}$-chondrite with a very long terrestrial age. $M e$ teoritics and Planetary Science 32:769-73.

Schiekel Th, Sudbrock F, Herpers U, Gloris M, Lange HJ, Leya I, Michel R, Dittrich-Hannen D, Synal H-A. Suter M, Kubik PW, Blann M, Filges D. 1996. Nuclide production by proton-induced reactions on elements $(6<\mathrm{Z}<29)$ in the energy range from 200 to $400 \mathrm{MeV}$. Nuclear Instruments and Methods in Physics Research B114:91-119.

Schultz L, Franke L, Kruse H. 1996. Helium, neon and argon in meteorites: a data compilation update 1996. Mainz: Max-Planck-Institut für Chemie. Computer diskette.

Schultz L, Scherer P, Specter B, Wlotzka F, Sipfel J, Schlüter T, Merchel S, Herpens U, Newton J, Franchi IA, Pillinger CT, Leya I, Neumann S, Neupert U, Michel R, Kubik PW, Synal HA, Biondi G, Hajdas I, Ivy-Ochs S, Suter M. 1998. Ten new meteorites from the Ténéré desert (Niger): classification, noble gases, cosmogenic radionuclides and terrestrial ages. Meteoritics and Planetary Science 33:A138.

Scott ERD, McKinley SG, Keil K, Wilson IE. 1986. Recovery and classification of thirty new meteorites from Roosevelt County, New Mexico. Meteoritics and Planetary Science 21:303-9

Sipiera PP, Becker MJ, Kawachi Y. 1987. Classification of twenty-six chondrites from Roosevelt County, New Mexico. Meteoritics and Planetary Science 22:151-5.

Sisterson JM, Jull AJT, Beverding A, Koehler AM, Castaneda C, Vincent J, Donahue DJ, Englert PAJ, Gans C, Young J, Reedy RC. 1994. Revised solar cosmic ray fluxes estimated using measured depth profiles of ${ }^{14} \mathrm{C}$ in lunar rocks: the importance of good cross section measurements. Nuclear Instruments and Methods in Physics Research B92:510-2.

Sisterson JM, Kim K, Beverding A, Englert PAJ, Caffee 
M, Jull AJT, Donahue DJ, McHargue L, Castaneda C, Vincent J, Reedy RC. 1997a. Measurement of proton production cross sections of ${ }^{10} \mathrm{Be}$ and ${ }^{26} \mathrm{Al}$ from elements found in lunar rocks. Nuclear Instruments and Methods in Physics Research B123:324-9.

Sisterson JM, Kim K, Beverding A, Englert PAJ, Caffee MW, Vincent J, Castaneda C, Reedy RC. 1997b. Measuring excitation functions needed to interpret cosmogenic nuclide production in lunar rocks. In: Duggan JL, Morgan IL, editors. Conference on Applications of Accelerators in Research and Industry. AIP Conference Proceedings 392:811-4.

Sisterson JM, Kim K, Caffee MW, Reedy RC. 1997c. ${ }^{10} \mathrm{Be}$ and ${ }^{26} \mathrm{Al}$ production in lunar rock 68815 : Revised production rates using new cross section measurements. Lunar and Planetary Science 28:1327-8.

Spergel MS et al. 1986. Proceedings of the 10th Lunar and Planetary Science Conference. Journal of Geophysical Research 91(B4):D483.

Stelzner Th, Heide K, Bischoff A, Weber D, Scherer P, Schultz L, Happel M, Schrön W, Neupert U, Michel R, Clayton RN, Mayeda TK, Bonani G, Ivy-Ochs S, Suter M. 1999. An interdisciplinary study of weathering effects in ordinary chondrites from the Acfer region, Algeria. Meteoritics and Planetary Science 34:
787-94.

Suess H, Wänke H. 1962. Radiocarbon content and terrestrial age of 12 stony meteorites and one iron meteorite. Geochimica et Cosmochimica Acta 26:475-80.

Vogt S, Herzog GF, Reedy RC. 1990. Cosmogenic nuclides in extraterrestrial materials. Reviews in Geophysics 28:253-75.

Welten KC, Alderliesten C, Van der Borg K, Lindner L, Loeken T, Schultz L. 1997. Lewis Cliff 86360: an Antarctic L-chondrite with a terrestrial age of 2.35 million years. Meteoritics and Planetary Science 32:775-80.

Wieler R, Graf Th, Signer P, Vogt S, Herzog GF, Tuniz C, Fink D, Fifield LK, Klein J, Middleton R, Jull AJT, Pellas P, Masarik J, Dreibus G. 1996. Exposure history of the Torino meteorite. Meteoritics and Planetary Science 31:265-72.

Wlotzka F, Jull AJT, Donahue DJ. 1995. Carbon-14 terrestrial ages of meteorites from Acfer, Algeria. Workshop on meteorites from cold and hot deserts. Houston: Lunar and Planetary Institute. Lunar and Planetary Institute Technical Report 95-02:72-3.

Ziegler JF, Biersack J, Littmark U. 1989. The stopping and range of ions in solids. New York: Pergamon Press. 